Artigo Teórico-empírico

\section{Incerteza das Provisões de Sinistros a partir da Análise das Demonstrações Contábeis}

\author{
Uncertainty of Claims Provisions from the Analysis of Financial Statements
}

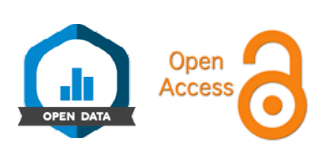

\author{
Roberto Bomgiovani Cazzari*1 $\odot$ \\ Guilherme R. Fernandes Moreira ${ }^{1}$
}

\section{RESUMO}

Objetivo: tendo em vista o nível de transparência atual das demonstraçôes financeiras de seguradoras brasileiras, este trabalho buscou avaliar se era possível estimar a suficiência das provisóes técnicas de sinistros por ela estimadas. Por serem passivos de prazo ou montante incertos, as estimativas de provisóes podem estar subestimadas (comprometendo as seguradoras) ou superestimadas (onerando os sócios), o que justifica a questáo de pesquisa. Métodos: após a análise das demonstraçóes financeiras de 31 seguradoras no Brasil, notou-se que os critérios de divulgaçáo de desenvolvimento de sinistros variavam substancialmente. Assim, foram selecionadas cinco seguradoras que adotaram procedimentos similares e permitiram a aplicação do modelo de bootstrapping para a estimação do nível de suficiência das provisões. Resultados: a aplicação do modelo em tela revelou que há indícios de que as seguradoras podem fazer uso do gerenciamento de resultados por meio da estimação de provisões técnicas de sinistros, repartindo o ônus do risco de insuficiência das provisóes de forma diferente entre segurados e acionistas. Conclusáo: há diferenças nos níveis relativos de provisōes de sinistros reconhecidos pelas seguradoras, demonstrando que há um possível gerenciamento de resultados sendo aplicado por meio de sua estimação.

Palavras-chave: provisões de sinistros; suficiência; disclosure.

\section{ABSTRACT}

Objective: considering the current level of transparency in the financial statements of Brazilian insurers, this study sought to assess whether it was possible to estimate the sufficiency of the claims reserves estimated by it. As they are liabilities with an uncertain term or amount, the estimates of these reserves may be underestimated (compromising the insurers) or overestimated (burdening the shareholders), which justifies the research question. Methods: after analyzing the financial statements of 31 insurance companies in Brazil, it was noted that the criteria for disclosing claims development varied substantially. Thus, five insurers were selected that adopted similar procedures and allowed the application of the bootstrapping model to estimate the sufficiency level of the provisions. Results: the application of the model revealed that there are indications that insurers can make use of earnings management through the estimations of the claims reserves, spreading the burden of claims insufficiency risk differently between policyholders and shareholders. Conclusion: there are differences in the relative amount of claims recognized by the insurers, showing a possible earnings management practice being applied through the claims measurement.

Keywords: claims reserves; sufficiency; solvency; disclosure.

\footnotetext{
* Autor Correspondente.

1. Universidade Federal de São Paulo, Escola Paulista de Políica, Economia e Negócios, Osasco, SP, Brasil.

Como citar: Cazzari, R. B., \& Moreira, G. R. F. (2022). Incerteza das provisões de sinistros a partir da análise das demonstrações contábeis. Revista de Administração Contemporânea, 26(3), e200400. https://doi.org/10.1590/1982-7849rac2022200400.por
}

Publicado em Early Access: 08 de Novembro, 2021.

Designado a essa edição: 10 de Dezembro, 2021.
Classificação JEL: M4.

Editores-chefes: Wesley Mendes-da-Silva (Fundação Getulio Vargas, EAESP, Brasil) Marcelo de Souza Bispo (Universidade Federal da Paraíba, PPGA, Brasil) (I) Editores Convidados: João Vinícius de França Carvalho (Universidade de São Paulo, FEA, Brasil) (0) Eduardo Flores (Universidade de São Paulo, FEA, Brasil) (c) Emiliano A. Valdez (University of Connecticut, EUA) Pareceristas: Os indivíduos revisores não autorizaram a divulgação de suas identidades. Relatório de Revisão por Pares: A disponibilização do Relatório de Revisão por Pares não foi autorizada pelos revisores. Recebido: 30/11/2020 Última versão recebida em: 23/07/2021 Aceite em: $27 / 07 / 202$

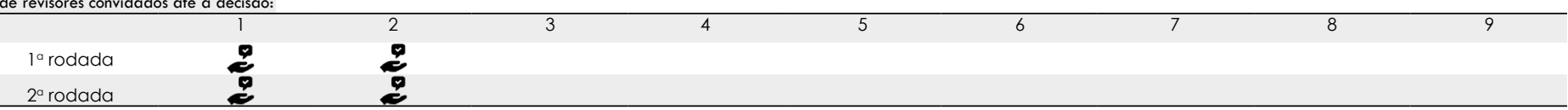




\section{INTRODUÇÃO}

Por serem produtos financeiros que contribuem para a sociedade através do compartilhamento de riscos e terem um papel fundamental em uma economia em desenvolvimento, a saúde financeira das seguradoras é de suma importância para a economia de um país. Se os custos de uma seguradora não forem bem dimensionados e esta não possuir capital para indenizar seus segurados, a seguradora pode se tornar insolvente e causar enormes danos à sociedade. Diferentemente de outras indústrias, as seguradoras só conhecem o custo total dos serviços vendidos durante um intervalo contábil após um longo período. Dependendo do tipo de seguro ofertado e do evento gerador do sinistro, o custo final pode demorar dias, meses ou até mesmo décadas para ser conhecido (Friedland, 2010).

Devido às incertezas nos prazos de liquidação dos sinistros e no valor que será pago por cada sinistro, as seguradoras devem manter provisôes de sinistros. Do ponto de vista contábil e seguindo a orientação do International Accounting Standard (IAS) na publicação IAS 37 Provisions, Contingent Liabilities and Contingent Assets, o Comitê de Pronunciamentos Contábeis (CPC), por meio do CPC 25, define 'provisóes' como "passivos de prazo ou valor incertos" (Comitê de Pronunciamentos Contábeis [CPC], 2009, p. 4). O mesmo pronunciamento define 'passivo' como "obrigaçáo presente da entidade, derivada de eventos já ocorridos, cuja liquidaçáo se espera que resulte em saída de recursos da entidade capazes de gerar benefícios econômicos" (CPC, 2009, p. 5). Logo, dada uma determinada data contábil, a seguradora deve dispor de ativos para o pagamento de sinistros que ocorreram até essa data contábil, mesmo que a seguradora não tenha conhecimento destes sinistros (Mano \& Ferreira, 2009).

Nesse âmbito, as provisóes técnicas frequentemente são o item mais representativo no lado passivo do balanço patrimonial de uma seguradora, na medida em que elas representam as estimativas que seguradoras devem manter para arcar com as obrigaçôes inerentes presentes à atividade securitária. Para que se verifique a importância de seus números, somente em 2019, segundo dados da Superintendência de Seguros Privados (Susep), as provisóes perfizeram um montante de $\mathrm{R} \$ 1$ 1.084.199.731.882, representando aproximadamente $14,84 \%$ do PIB brasileiro.

Nesse sentido, o correto dimensionamento das provisóes é fundamental para garantir a liquidez e a solvência das companhias seguradoras, o que exige que estas sejam bem estimadas. Logo, o resultado financeiro dessas companhias está diretamente ligado ao valor atribuído às provisões. Assim, se há superdimensionamento destas, a distribuiçáo dos lucros aos acionistas pode ser comprometida, diminuindo a atratividade e o retorno financeiro do investidor. Caso as provisóes técnicas estejam subdimensionadas, a empresa irá distribuir lucros indevidos e não possuirá garantias para honrar seus compromissos, podendo tornar-se insolvente (Mano \& Ferreira, 2009).

Os problemas gerados por provisóes técnicas subdimensionadas não terminam na seguradora e em seus clientes. Eles afetam todo o mercado, já que caso uma seguradora se torne insolvente, a credibilidade de todo o setor será afetada, criando insegurança e diminuindo a confiança dos clientes em relaçáo a produtos baseados no 'risco'. Dessa forma, observa-se a grande responsabilidade das companhias no correto dimensionamento das provisóes técnicas, estendendo-se da seguradora à sociedade (Mano \& Ferreira, 2009). Complementarmente, a estimação da carga de distribuição de probabilidade dos sinistros não pagos é de suma importância para o gerenciamento de riscos, para a escolha da política de investimentos e para a alocação de capital da companhia, além de ser fundamental para atender aos requerimentos de Solvência II e de órgãos internacionais (Christiansen \& Niemeyer, 2014).

Assim, dada a incerteza intimamente associada às estimativas das provisóes, este trabalho partiu do seguinte questionamento:

É possível inferir, por meio das demonstraçóes financeiras das entidades securitárias brasileiras, o nível de suficiência das provisões reconhecidas por essas entidades?

Tendo em vista o preâmbulo, este artigo avaliou se tal possibilidade era viável dado o nível de disclosure atual das seguradoras, focando-se unicamente nas provisóes de sinistros. Estas são definidas como os montantes de obrigaçôes estimadas para a liquidação de todos os sinistros que ocorreram até certa data de fechamento contábil e que ainda não foram pagos, independentemente de se eles foram comunicados ou não às seguradoras (Mano \& Ferreira, 2009). Se for possível obter a distribuição de probabilidades associada aos montantes de provisōes de sinistros, será possível que o leitor das demonstrações financeiras, sob um conjunto de hipóteses previamente adotadas, consiga estimar impactos da variabilidade das provisóes técnicas de sinistros, permitindo que seu espectro de análise seja ampliado.

Verificou-se que a tarefa proposta por este trabalho é possível, mas dadas as diferenças no formato de divulgaçáo das informaçóes, é essencial que o usuário da informaçáo contábil tenha cuidado para a análise de cada seguradora individualmente.

Este artigo, portanto, fez um esforço prático de mostrar como se estima tal distribuiçáo de probabilidades para um grupo de seguradoras que divulgaram suas informaçóes de desenvolvimento de sinistros em notas 
explicativas. Para tanto, foi aplicado o modelo estocástico de England e Verrall (1999) para calcular a distribuição de probabilidade associada ao montante de provisóes de sinistros de um grupo de seguradoras, considerando-se as peculiaridades no formato de divulgação de cada uma.

Posteriormente, analisaram-se suas estimativas de provisões de sinistros reconhecidas nas demonstraçóes financeiras, com vistas a verificar sua probabilidade de suficiência. Pode-se dizer, nesse sentido, que o artigo se enquadra como um estudo que visa, por meio de um exercício empírico, a inferir sobre a incerteza associada aos montantes de provisóes de sinistros, propondo um método de análise prospectivo.

O trabalho se estruturou da seguinte maneira: inicialmente, é apresentado o marco regulatório que consubstancia o tema em questão. Posteriormente, é feita uma revisão de literatura, dividindo-a em modelos de provisóes de sinistros e teoria do disclosure. Após tal etapa, apresentam-se a metodologia adotada e os resultados obtidos. Finalmente, são tecidas as consideraçóes finais, ressaltando as limitaçóes do trabalho.

\section{MARCO REGULATÓRIO}

A Susep é responsável pela publicação da norma que trata do dimensionamento das provisões, a circular 517/2015. A resoluçáo do Conselho Nacional de Seguros Privados (CNSP) 321/2015 também contém várias orientaçóes que as supervisionadas pela Susep devem seguir no tocante às provisóes técnicas (Conselho Nacional de Seguros Privados, 2015). De acordo com a norma em tela, toda seguradora obrigatoriamente deve calcular a Provisão de Sinistros a Liquidar (PSL) e a Provisão de Sinistros Ocorridos e Não Avisados (IBNR) (Superintendência de Seguros Privados [Susep], 2015). Enquanto a primeira deve ser constituída com o objetivo de cobrir os valores esperados a liquidar de sinistros ocorridos e já avisados à seguradora até a data contábil, a segunda deve conter os valores esperados a liquidar de sinistros ocorridos e ainda não avisados à seguradora até a data contábil. Nesse âmbito, o cômputo total de sinistros ocorridos e ainda não pagos (IBNP) é dado pela soma da PSL e IBNR.

Vale a pena complementar que todas as provisóes estimadas são brutas de importâncias a serem recuperadas em resseguro, de tal sorte que estes valores são reconhecidos no ativo, por meio das contas de ativos de resseguro. Adicionalmente, é mister acrescentar que todas as provisóes de sinistros apresentadas sáo líquidas dos efeitos de salvados e de IBNER (provisóes de eventos ocorridos, mas não suficientemente estimados).
Além de definir as provisões técnicas, a circular 517/2015 também dispóe que as seguradoras devem utilizar métodos estatísticos e atuariais com base em consideraçóes realistas para avaliar as obrigaçóes dos contratos de seguro.

Existem diversos órgãos internacionais que publicam pronunciamentos técnicos com vistas a orientar as seguradoras na elaboraçấo de tais estimativas. Dentre esses órgãos, é possível citar o Casualty Actuarial Society (CAS), o Society of Actuaries (SOA) e o Actuarial Standards Board (ASB), sendo o último responsável pelo desenvolvimento e publicação dos relatórios Actuarial Standard of Practice (ASOPs) (Actuarial Society Board, 2011a, 2011b; Casualty Actuarial Society, 2014).

Concomitantemente aos esforços enveredados em cenário norte americano, em 2009 foi publicada a diretriz europeia 2009/138/EC (ou Acordo de Solvência II) (Council of the European Union, 2009), com o intuito de reduzir os riscos relacionados à insolvência de seguradoras no mercado europeu (Carvalho \& Carvalho, 2019). Nela, foram dispostas alterações e novos critérios que as seguradoras europeias deveriam instituir no dimensionamento das provisōes técnicas.

Adicionalmente, o CPC 11, que trata dos contratos de seguro e é correlato ao IFRS 4, prevê que toda seguradora elabore a cada data de balanço um Teste de Adequação de Passivo (TAP), com vistas a testar se o seu passivo associado aos contratos de seguro está adequadamente mensurado. Para tanto, as seguradoras são obrigadas a utilizar estimativas correntes dos fluxos de caixa de seus contratos de seguro. Se for detectado que o montante de passivo é insuficiente, toda a deficiência deve ser imediatamente reconhecida no resultado (CPC, 2008).

Nesse sentido, Caldas, Curvello e Rodrigues (2016) retratam que se a insuficiência apurada estiver relacionada às provisóes de prêmios ou provisôes matemáticas, a seguradora deverá constituir uma Provisão Complementar de Cobertura (PCC). Caso a insuficiência se dê nas provisóes de sinistros, o aumento deverá ocorrer na própria.

\section{REVISÃO DE LITERATURA}

\section{Modelos de provisões de sinistros}

McClenahan (2003) aponta que até a década de 1970, o conceito de alcance de estimativas razoáveis era pouco aplicado no processo de dimensionamento de provisóes técnicas de sinistros, e que o desenvolvimento desse conceito se deu a partir de Anker (1973) e Skurnick (1973). Nesse sentido, Anker (1973) discorre sobre a possibilidade de se estabelecer um intervalo para as provisóes estimadas, que 
pode ser realizado de forma subjetiva ou estatística, esta última por meio de métodos estocásticos.

Logo, os métodos determinísticos eram largamente aplicados. Dentre eles, o método chain ladder era dominante na literatura atuarial para estimar o montante de sinistros ocorridos e ainda não pagos, o IBNP. Com isso, há considerável documentação disponível sobre a base estatística do método chain ladder, destacando-se Taylor e Ashe (1983), Mack (1993) e England e Verrall (1999, 2002), de grande valia para o entendimento teórico da base estatística do modelo.

Simultaneamente ao esforço de Skurnick (1973), Bornhuetter e Ferguson (1972) apresentaram um paper seminal sobre o tema, desenvolvendo o modelo determinístico de Bornhuetter-Ferguson, também largamente aplicado na prática. Tal modelo utiliza uma taxa de sinistralidade presumida, obtida a partir da experiência histórica.

Indubitavelmente, os trabalhos anteriores foram imprescindíveis para que se desenvolvesse uma extensa linha de pesquisa de estimação de provisões técnicas de sinistros. Abordando inicialmente métodos determinísticos, como o chain ladder, a literatura foi se expandindo para os métodos estocásticos, dado o consequente avanço computacional, o que permitiu que diferentes simulaçôes mais complexas fossem adotadas.

Assim, diversos modelos estocásticos foram construídos ao longo dos últimos anos com o intuito de produzir estimativas das distribuiçóes de probabilidade associadas ao montante de IBNP, dado que é possível obter uma gama de informaçóes que o modelo determinístico não é capaz de fornecer (England \& Verrall, 1999).

Apesar de sua simplicidade, o método chain ladder utiliza premissas que podem facilmente falhar dependendo dos dados utilizados no estudo. $\mathrm{O}$ método chain ladder não é indicado quando os dados utilizados são voláteis ou quando são sensíveis a variaçóes externas, como a influência da inflação (Lemaire, 1985). Além disso, o método dispóe apenas de uma estimativa pontual da provisão técnica (Chase, 2015). Essas limitaçóes, quando analisadas em conjunto, incentivaram a academia atuarial a desenvolver métodos estocásticos.

Nesse âmbito, os métodos estocásticos podem ser divididos em dois grandes grupos: paramétricos e não paramétricos. Nos métodos paramétricos, são apresentados conjuntos de estimadores cuja principal premissa é a de que os dados iniciais utilizados seguem uma distribuição estatística determinada. Os métodos paramétricos não são o foco deste trabalho e, portanto, não serão abordados no texto. Os métodos náo paramétricos, por outro lado, não assumem que os dados apresentam uma distribuição de probabilidade específica a priori (Berrar, 2019).
Dentre os métodos estocásticos não paramétricos, o método de reamostragem por bootstrap é uma técnica capaz de gerar uma distribuição de probabilidade empírica que pode ser utilizada para testar a acurácia de estimativas e fazer inferências estatísticas sobre um conjunto de dados (Berrar, 2019). Utilizando os resíduos de Pearson, essa metodologia foi proposta por England e Verrall (1999). Neste trabalho, será apresentado o método de bootstrap não paramétrico para produzir estimativas da variabilidade das provisóes técnicas de sinistros e estabelecer um intervalo de confiança para a provisão técnica de IBNP com base nos dados divulgados publicamente por um grupo de seguradoras. Nesse âmbito, a metodologia em tela será desenvolvida analiticamente na próxima seção deste trabalho.

Mais recentemente, uma gama de metodologias mais complexas vem sendo apresentada pela comunidade científica. Sriram e Shi (2020) apresentaram uma nova perspectiva de estimaçáo de provisões de sinistros por meio de um modelo estocástico de Dirichlet. Para tanto, os autores usaram dados de sinistros provenientes de seguradoras americanas, comparando a inferência frequentista $\mathrm{e}$ bayesiana.

Preocupados com a estrutura de correlação nos dados, Badounas e Pitselis (2020) apresentaram um modelo de estimação da provisão de sinistros em um modelo longitudinal quantílico.

Por sua vez, alguns trabalhos vêm adotando o uso de redes neurais para que se estimem os montantes de provisóes de sinistros. Nesse âmbito, Gabrielli (2019) usaram a técnica de redes neurais para melhorar o modelo de estimação de provisóes de sobredispersão de Poisson. $\mathrm{Na}$ mesma linha, Ramos-Pérez, Alonso-González e Nuñez-Velazquez (2020) também apresentaram um modelo estocástico de estimação de provisóes de sinistros usando redes neurais. Tanto Lindholm, Verrall, Wahl e Zakrisson (2020) como Balona e Richman (2020) propõem o uso de machine learning para as estimativas de provisóes de sinistros, sendo que o segundo trabalho se focou no IBNR. Náo obstante, Lopez e Milhaud (2020) propóem um método usando um algoritmo CART (Classification and Regression Tree) considerando os atrasos e o desenvolvimento de sinistros longos. Conforme se vislumbra, mais recentemente, há um predomínio de propostas que fazem uso de métodos computacionais avançados.

Em cenário nacional, ainda existe uma escassez de trabalhos que abordam a questáo. Dentre os trabalhos desenvolvidos, destaca-se o trabalho de Carvalho e Carvalho (2019), que utilizaram tanto uma abordagem paramétrica quanto não paramétrica (esta última por bootstrap) para estimar a IBNR associada aos ramos de seguros de automóveis e responsabilidade civil facultativa de uma seguradora brasileira. 
Já Vieira (2016) abordou as metodologias determinísticas de provisão de sinistros, analisando quais são as metodologias aplicadas na prática em cenário nacional e internacional. Por sua vez, Yuassa (2018) aplicou também a metodologia estocástica por bootstrap com vistas a estimar a variabilidade das provisóes de sinistros.

Finalmente, Costa e Yui (2018) aplicaram um processo hierárquico analítico para comparar os diferentes métodos de estimação da provisão IBNR de uma operadora de plano de saúde.

\section{Teoria do disclosure}

Indubitavelmente, o trabalho de Verrechia (2001) é um dos pilares da teoria do disclosure. De acordo com o referido autor, há três categorias de pesquisas relacionadas ao assunto em questão. A primeira categoria, denominada association-based disclosure, englobaria os trabalhos que estudam o efeito de divulgaçáo no que diz respeito a preços de equilíbrio de ativos e volume de negociação. Por sua vez, a segunda categoria, discretionary-based disclosure, abordaria os estudos que investigam como os administradores ou as próprias companhias exercem sua discricionariedade no sentido de definir sobre o que e como divulgar, o que também envolveria o conceito de divulgação voluntária. Finalmente, a terceira categoria, efficiency-based disclosure, abarca os trabalhos que discorrem sobre quais seriam os critérios de disclosure que seriam preferíveis considerando um cenário de ausência de conhecimento a priori da informação.

Nesse âmbito, este trabalho pondera aspectos atinentes à segunda categoria levantada por Verrechia (2001), na medida em que aborda como a divulgação dos critérios de desenvolvimento de sinistros pode impactar na mensuração da incerteza associada às provisões de sinistros, o que poderia ensejar a possibilidade de gerenciamento de resultados por parte dos administradores.

Considerando essa discussão, trabalhos recentes relacionaram o poder de discricionariedade de gestores no reconhecimento de níveis de provisão de sinistros e sua relação com os resultados divulgados. Mais detalhadamente, Berry-Stölze, Eastman e Xu (2018) investigaram a relação entre o excesso de confiança e práticas de mensuração de provisóes de sinistros na indústria de seguro de propriedade e responsabilidade civil nos EUA. Por sua vez, Hsu, Huang e Lai (2019) examinaram a relação entre o gerenciamento de provisōes e as características do comitê de auditores de seguradoras que operam com seguro de propriedade e responsabilidade civil. Os autores concluíram que tanto o comitê de auditores quanto as características dos conselhos influenciam nos valores divulgados. Não obstante, citando diversos trabalhos anteriores, os autores realçaram que o jeito mais comum de gerenciar resultado na indústria securitária é justamente por meio da estimação das provisóes de sinistros.

Discorrendo mais especificamente sobre a literatura internacional de disclosure aplicada às companhias securitárias, verifica-se que a maioria dos trabalhos está relacionada ao nível de responsabilidade social corporativa. Nesse sentido, os trabalhos de Ullah, Muttakin e Khan (2019), Das (2013), Sürdü, Çalışkan e Emel (2020) e Lock e Seele (2015) podem ser citados como exemplos.

No tocante ao nível de disclosure e seu impacto para a estimação dos riscos de ruína das companhias seguradoras, o trabalho de Hemrit e Arab (2011) estudou o componente de transparência do risco operacional de seguradoras tunisianas, relacionando-o aos conceitos de Solvência II. Em consonância, Höring e Gründl (2011) também analisaram as práticas de divulgação de informaçóes na indústria securitária europeia, relacionando o nível de transparência às diferentes características das firmas, como o tamanho, risco, lucratividade, dispersão de propriedade, país de atuação e tipo de seguro vendido, dentre outros fatores. Esforço similar foi empreendido por Malafronte, Starita e Porzio (2016), também em cenário europeu. No Brasil, o trabalho de Veras (2016) estudou o nível de evidenciação de contratos de seguros e passivo atuarial para as seguradoras brasileiras para a data-base de 31 de dezembro de 2015 .

Como se verifica, existe uma vasta literatura que busca avaliar o desempenho das seguradoras e sua relaçáo com sua solidez financeira, sem que haja necessariamente uma discussão teórica relacionada a como o nível de divulgação das companhias securitárias impacta nessa estimação. Dentre eles, convém citar os trabalhos recentes de Wang (2020) e Al-Yatama, Ali, Awadhi e Shamali (2020).

Logo, há uma lacuna na literatura de disclosure associada às entidades securitárias que este trabalho pretende preencher, na medida em que a maioria dos trabalhos não relaciona o nível de divulgação de informações à capacidade do usuário da informaçáo contábil em mensurar o risco de incerteza associada às provisóes de sinistros.

Dentre os trabalhos que se esforçaram em fazer algo similar, Mendes, Cardoso, Mário, Martinez e Ferreira (2014) estudaram como a presença de dados inconsistentes pode impactar os modelos tradicionais de insolvência. Por sua vez, Jackson e Wood (2013) também estudaram o desempenho da capacidade de prever insolvência relacionada aos modelos de risco de crédito no Reino Unido. 


\section{METODOLOGIA DE PESQUISA}

O artigo 156 da circular da Susep n. ${ }^{\circ}$ 517/2015 estabelece, por meio de seu inciso XIII, que:

"Deverão ser divulgadas em notas explicativas todas as informaçóes previstas por cada pronunciamento contábil aprovado pelo CPC, referendado pela Susep, e em especial as seguintes informaçóes, referentes às demonstraçoos individuais:

...

XIII - tabela de desenvolvimento de sinistros"

Conforme se verifica, as seguradoras estão obrigadas a divulgar o desenvolvimento de sinistros. Nesse sentido,
Caldas et al. (2016) explicam que tais informaçôes devem retroceder ao período do sinistro mais antigo para o qual ainda haja incerteza sobre o montante e a tempestividade do pagamento de indenização.

Apesar da obrigação da divulgação, nota-se empiricamente que não há um modelo uniforme da divulgação das informaçóes, de modo que se encontra uma miríade de padróes identificados, variando o grau de transparência em que as informaçóes são divulgadas, dificultando assim sua comparabilidade, o que exige que o esforço a ser empreendido para responder à questáo de pesquisa deste trabalho não seja factível para algumas companhias.

De modo geral, a granularidade na qual as informaçóes são apresentadas variam de acordo com a Tabela 1.

Tabela 1. Granularidade na divulgação das informações.

\begin{tabular}{|c|c|}
\hline Quesito & Consideraçóes \\
\hline $\begin{array}{l}\text { Quanto ao nível de agregação } \\
\text { das informaçóes }\end{array}$ & Se cabível, é usual que os dados sejam divulgados tanto para os dados consolidados quanto para os dados da controladora. \\
\hline Quanto ao tipo de sinistro & Se os sinistros são judicializados ou administrativos. \\
\hline Quanto ao resseguro & $\begin{array}{l}\text { Algumas seguradoras optam por divulgar as informaçóes de desenvolvimento de sinistros tanto brutos quanto líquidos } \\
\text { de resseguros. }\end{array}$ \\
\hline $\begin{array}{l}\text { Quanto aos salvados e } \\
\text { ressarcimentos }\end{array}$ & As seguradoras podem apresentar os resultados brutos ou líquidos de salvados e ressarcimentos. \\
\hline $\begin{array}{l}\text { Quanto à variabilidade dos } \\
\text { critérios de período }\end{array}$ & Os sinistros podem ser apresentados quanto ao ano de ocorrência, ano de registro, ano de aviso ou ano de subscrição. \\
\hline $\begin{array}{l}\text { Quanto à quantidade de } \\
\text { períodos de desenvolvimento }\end{array}$ & $\begin{array}{l}\text { Os sinistros frequentemente são apresentados em triângulos cujo desenvolvimento pode variar de um a dez períodos. } \\
\text { Algumas seguradoras podem optar por apresentarem mais de dez períodos, não sendo este o padrão mais usual. }\end{array}$ \\
\hline Quanto ao tipo de dado & $\begin{array}{l}\text { O desenvolvimento dos sinistros pode ser apresentado de diferentes maneiras, a saber: sinistros ocorridos ou sinistros } \\
\text { pagos. }\end{array}$ \\
\hline
\end{tabular}

Nota. Elaborado pelos autores.

Nesse ponto, convém detalhar mais incisivamente o último ponto abordado na Tabela 1 . Tal como Caldas et al. (2016) explicam, ao apresentar a tabela de desenvolvimento de sinistros incorridos em determinado ano e os saldos desse mesmo conjunto de sinistros nos anos seguintes, o usuário da informação financeira pode calcular o erro da estimativa da seguradora no intervalo dos períodos contemplados. Esse procedimento possibilita avaliar a precisão da estimativa dos sinistros no reconhecimento inicial, com vistas a auxiliar o processo de análises de fluxo de caixa futuro.

É imprescindível observar que mesmo o método chain ladder pode ser feito com base em diferentes origens de dados, possuindo estimativas diferentes calculadas de acordo com o tipo de dado. Ou seja, é possível obter uma estimativa do IBNP com base no desenvolvimento tanto de sinistros incorrido ${ }^{1}$ quanto de sinistros pagos.

Considerando que o presente estudo tem enfoque na aplicação de um método estocástico no cálculo do IBNP, o método chain ladder para o desenvolvimento de sinistros pagos $^{2}$ será apresentado, porque seu entendimento será essencial para a aplicação do modelo estocástico.

De forma breve, o método chain ladder utiliza dados incrementais e acumulados de sinistros já pagos e registrados para produzir uma estimativa acumulada pontual final. Essa estimativa representa o desenvolvimento total de todos os sinistros pagos em certo intervalo de tempo até o final do período de desenvolvimento escolhido, denominada de ultimate (England \& Verrall, 2002).

Para o modelo, assumiu-se que os dados estarão dispostos nos chamados triângulos de runoff (England \& Verrall, 2002). Considere um grupo de sinistros e que cada sinistro que compóe esse grupo é liquidado no ano de sua ocorrência ou em $n$ anos conseguintes (Schmidt, 2006). Esses sinistros podem ser modelados de forma incremental como se segue: 


$$
\left\{D_{i j}: i=1, \ldots, n ; j=1, \ldots, n-i+1\right\}
$$

em que:

$D$ pode representar o montante de sinistros pagos ou a contagem de sinistros;

$i$ se refere às linhas do triângulo e pode representar o ano de subscrição ou o ano de ocorrência, como no presente estudo;

$j$ se refere às colunas do triângulo e pode representar a quantidade de anos entre a ocorrência e a liquidação do sinistro, chamada de período de desenvolvimento.

O método chain ladder tem o objetivo de preencher os valores abaixo da diagonal principal dessa matriz e, com isso, obter o ultimate de cada $n$ ano de ocorrência, por meio da soma de cada linha da matriz preenchida do triângulo incremental.

O grupo de sinistros também pode ser modelado de forma acumulada por meio da fórmula:

$C_{i j}=\sum_{k=1}^{j} D_{i k}$

em que:

$C$ representa a soma dos valores de $D$ de cada ano de ocorrência $i$ até o ano de desenvolvimento $j$.

Após modelar o montante de sinistros de forma acumulada para cada ano de ocorrência e ano de desenvolvimento conhecidos, definem-se as estimativas dos fatores de desenvolvimento (FD), seguindo a equação:

$f_{j}=\frac{\sum_{k=1}^{n-j} c_{k, j+1}}{\sum_{k=1}^{n-j} c_{k j}} ; 1 \leq j \leq n-1$

em que $f_{j}$ representa a estimativa do fator de desenvolvimento do $j$-ésimo ano de desenvolvimento.

Em seguida, os fatores de desenvolvimento são acumulados pelo seguinte produtório:

$\hat{f}_{j}=\prod_{k=1}^{j} f_{j}$

O ultimate de cada período de ocorrência é entáo calculado por meio da aplicaçáo do $\hat{f}_{j}$ para cada período de ocorrência, conforme:

$\hat{C}_{i, n}=C_{i, n+1-i} \times \hat{f}_{j} ; 0 \leq i \leq n$

em que $\hat{C}_{i, n}$ representa o ultimate de cada ano de ocorrência.
É esperado que o desenvolvimento dos sinistros mais recentes ocorra de forma semelhante ao desenvolvimento dos sinistros observados no passado.

O resultado do método chain ladder é uma estimativa simples dos valores ultimate de cada $n$ ano de ocorrência. Para obter a provisão e IBNP devemos subtrair do ultimate de cada ano de ocorrência do valor da diagonal principal do triângulo acumulado de pagamentos de sinistros, conforme exemplificado abaixo:

$I B N P=\sum_{i=1}^{n} \hat{C}_{i, n}-C_{i, n+1-i}$

Tendo em vista que esse modelo é determinístico e, por consequência, apenas fornece uma estimativa pontual do IBNP, será apresentado o método estocástico não paramétrico por bootstrap, tal como sugerido por England e Verrall (1999).

Considere um conjunto de dados com distribuição empírica de tamanho n e que cada dado observado recebe uma probabilidade $1 / n$. A amostra bootstrap pode ser definida como sendo aleatória, de tamanho $n$ e retirada da amostra inicial com reposiçấo. Dessa forma, um dado qualquer da amostra inicial pode aparecer diversas vezes ou até mesmo nenhuma vez na amostra bootstrap.

Primeiramente deve-se modelar o triângulo de sinistros pagos de forma acumulada e obter os fatores de desenvolvimento para cada período de desenvolvimento utilizando a Equação (7):

$f_{j}=\frac{\sum_{k=1}^{n-j} C_{k, j+1}}{\sum_{k=1}^{n-j} C_{k j}} ; 1 \leq j \leq n-1$

A seguir, cria-se um triângulo mantendo apenas a diagonal principal com os valores acumulados dos sinistros pagos e estimando os valores acima da diagonal principal. Esses valores serão estimados de forma recorrente dividindose o valor do período de desenvolvimento $n$ pelo fator de desenvolvimento de $n-1$.

Deve-se então modelar os triângulos incrementais a partir do triângulo acumulado original e do triângulo acumulado estimado e, por meio da aplicação da Equação (8) em cada posição do triângulo, calcular o triângulo de resíduos adimensionais de Pearson $\hat{r}_{i, j}$ :

$\hat{r}_{i, j}=\frac{D_{i, j}-m_{i, j}}{\sqrt{m_{i, j}}}$

em que:

$D_{i, j}$ representa o valor na posição $(i, j)$ do triângulo incremental original;

$m_{i, j}$ representa o valor na posição $(i, j)$ do triângulo incremental estimado. 
Com o triângulo de resíduos construído, é calculada a variância dos resíduos por meio da Equação (9):

$\phi=\frac{\sum_{i=1}^{N} \hat{r}_{i}^{2}}{N-p}$

em que:

$N$ representa o total de observaçóes;

$p$ representa o número de parâmetros estimados pelo modelo.

Nesse âmbito, Albarrán e Alonso (2011) recomendam que o modelo estimado seja:

$\eta_{i, j}=C+\alpha_{i}+\beta_{j}$

em que:

$\alpha_{0}=\beta_{0}=0$;

$i$ é o número de anos de ocorrência menos 1 ;

$j$ é o número de anos desenvolvimento menos 1 .

Aplica-se então o método bootstrap através da construção de um novo triângulo contendo uma reamostragem dos resíduos de Pearson realizada com reposiçáo. Todos os resíduos devem ter a mesma probabilidade de serem escolhidos na reamostra.

A seguir, é necessário fazer a regeneração dos valores incrementais de sinistros pagos a partir do triângulo de resíduos reamostrado no passo anterior, de acordo com a Equação (11):

$$
\widehat{D}_{i, j}=\hat{r}_{i, j} \times \sqrt{m_{i, j}}+m_{i, j}
$$

O triângulo incremental resultante do passo anterior deve ser acumulado e uma nova estimativa de IBNP deve ser calculada pelo método chain ladder tradicional.

O processo estará completo depois de se repetir a reamostragem do triângulo de resíduos de Pearson, a regeneração dos valores de sinistros pagos e o cálculo de novas estimativas de IBNP várias vezes.

Para o esforço empírico consubstanciado, o trabalho foi empreendido junto aos dados divulgados publicamente pelas demonstraçóes financeiras de cinco seguradoras brasileiras, referentes ao ano de 2019. Para definir quais seguradoras seriam utilizadas no estudo, foram analisadas as demonstraçóes financeiras de trinta e uma companhias seguradoras brasileiras que atuaram até dezembro de 2019, de modo que elas compunham mais de $90 \%$ do cômputo de prêmios emitidos no mercado brasileiro em 2019 para seguros não vida.

A Tabela 2 apresenta a lista das 31 seguradoras avaliadas, bem como seu código Susep e principais ramos de atuação.

Tabela 2. Seguradoras inicialmente analisadas.

\begin{tabular}{|c|c|}
\hline Código SUSEP & Principais ramos de atuação \\
\hline 06467 & Automóvel, RCF, Compreensivo Empresarial e Compreensivo Residencial \\
\hline 05177 & Automóvel, Patrimonial, Transporte, Pessoas e Rural \\
\hline 02798 & Transportes, Responsabilidades, Riscos Financeiros e Patrimonial \\
\hline 02852 & Garantia Extendida, Garantia Setor Público e Privado, Patrimonial e Responsabilidades \\
\hline 05355 & Automóvel, RCF e Assistência \\
\hline 01414 & Riscos Financeiros, Responsabilidades, Patrimonial e Transpostes \\
\hline 05444 & VGBL, Seguros de Vida, Automóvel e PGBL \\
\hline 06785 & Vida e Rural \\
\hline 05631 & Vida em Grupo, Habitacional fora do SFH, Automóvel, Compreensivo Empresarial e Habitacional \\
\hline 02933 & Riscos Diversos, Garantia Extendida e Microseguro de Danos \\
\hline 06513 & Pessoas Coletivo, Pessoas Individual, Responsabilidades, Transpostes e Riscos Financeiros \\
\hline 04669 & Riscos Financeiros, Rural, Transportes, Petróleo e Responsabilidades \\
\hline 06122 & Patrimonial, Responsabilidades e Riscos Financeiros \\
\hline 05908 & Automóvel, RCF, Acidentes Pessoais e Prestamista \\
\hline 01571 & Patrimonial, Transportes e Responsabilidades \\
\hline 06572 & Automóvel, Patrimonial e Transportes \\
\hline 05142 & Vida em Grupo, Prestamista e Acidentes Pessoais, \\
\hline 05185 & Automóvel, Patrimonial e Vida, Transportes \\
\hline
\end{tabular}


Tabela 2. Seguradoras inicialmente analisadas (Continuação).

\begin{tabular}{cl}
\hline Código SUSEP & \\
\hline 02062 & Garantia Extendida \\
\hline 06238 & Automóvel, Patrimonial, Rural e Aeronáuticos \\
06602 & Automóvel, Patrimonial e Transportes \\
\hline 05886 & Automóvel, RCF, Compreensivos Empresarial, Fiança Locatícia e Compreensivo Residencial \\
03069 & Garantia e Fiança Locatícia \\
06751 & Transportes, Automóvel, Patrimonial e Pessoas \\
05720 & Automóvel, Patrimonial, Transportes, Pessoas Coletivo e Rural \\
05118 & Automóvel, RCF, Assistência, Compreensivos Residencial e Compreensivo Condomínio \\
06190 & Automóvel, Patrimonial e Vida \\
06653 & Garantia Setro Público, Prestamista, Habitacional Fora do SFH e Rural \\
03671 & Prestamista e Automóvel \\
05495 & Garantia Extendida, Riscos Diversos, Automóvel, Vida em Grupo e Prestamista \\
06564 & Compreensivo Residencial, Habitacional, Compreensivo Empresarial e Riscos Diversos \\
\hline
\end{tabular}

Nota. Elaborado pelos autores.

Como um dos objetivos do trabalho é verificar o nível de suficiência das provisóes (em conjunto ao nível de capital de solvência) associada à estimativa de IBNP pelo método de England e Verrall (1999), é necessário que para que essa comparação seja válida, os dados disponibilizados nos triângulos de runoff das notas explicativas estejam agrupados por ano de ocorrência, tendo em vista que o modelo utilizado parte dessa premissa.

As outras condições utilizadas na escolha das seguradoras se referem à existência de pelo menos dez anos de desenvolvimento de sinistros nos triângulos; ao agrupamento dos sinistros disponibilizado ser na forma de sinistros pagos acumulados; e, por fim, ao fato de que os dados apresentados sejam brutos de resseguro.

Das 31 seguradorasanalisadas, apenas cinco apresentaram os dados de desenvolvimento de sinistros conforme explicitado. Para demonstrar a dificuldade na escolha das seguradoras para o estudo consubstanciado, as Tabelas 3, 4, 5 e 6 apresentam a variabilidade que existe no formato da divulgação dos dados das 31 seguradoras analisadas.

A Tabela 3 demonstra que das 31 seguradoras analisadas, dez apresentam o desenvolvimento dos sinistros a partir do ano de aviso, 18 a partir do ano de ocorrência e três a partir do ano de registro dos sinistros.

Por sua vez, foram identificados dez períodos de desenvolvimento diferentes dentre as 31 seguradoras. A Tabela 4 apresenta a quantidade de seguradoras para cada classe de período.

Já a Tabela 5 indica que 16 companhias dentre as 31 analisadas apresentam o triângulo de desenvolvimento de sinistros pagos acumulados.
Tabela 3. Variabilidade dos critérios de período.

\begin{tabular}{lc}
\hline $\begin{array}{l}\text { Desenvolvimento dos sinistros a } \\
\text { partir da data de }\end{array}$ & Quantidade de seguradoras \\
\hline Aviso & 10 \\
Ocorrência & 18 \\
Registro & 3 \\
\hline
\end{tabular}

Nota. Elaborado pelos autores.

Também foi possível verificar que 27 seguradoras analisadas apresentavam triângulos de desenvolvimento brutos de resseguro, de modo que para quatro seguradoras, a nota explicativa não permitia identificar se os dados eram brutos ou líquidos de resseguro.

Tabela 4. Variabilidade dos períodos de desenvolvimento.

\begin{tabular}{|cc}
\hline Período de desenvolvimento* $^{*}$ & Quantidade de seguradoras $^{*}$ \\
\hline 20152019 & 2 \\
20142019 & 7 \\
$2014+2019$ & 3 \\
20132019 & 1 \\
$2013+2019$ & 1 \\
20122019 & 2 \\
20112019 & 4 \\
20102019 & 6 \\
20092019 & 4 \\
$2008+2019$ & 1 \\
\hline
\end{tabular}

Nota. Elaborado pelos autores. * Símbolo “+” significa que os sinistros de períodos anteriores estáo acumulados no período indicado. 
Tabela 5. Quantidade de seguradoras que possuem triângulo de runoff de sinistros pagos acumulados.

\begin{tabular}{lc}
\hline $\begin{array}{c}\text { Possui triângulo de sinistros } \\
\text { pagos? }\end{array}$ & Quantidade de seguradoras \\
\hline Sim & 16 \\
Não & 15 \\
\hline
\end{tabular}

Nota. Elaborado pelos autores.

Tabela 6. Quantidade de seguradoras que possuem triângulo de runoff bruto de resseguro.

\begin{tabular}{lc}
\hline Sinistros estão brutos de resseguro? & Quantidade de seguradoras \\
\hline Sim & 27 \\
Não & 0 \\
Não informado & 4 \\
\hline
\end{tabular}

Nota. Elaborado pelos autores.
Os dados utilizados nesta análise encontram-se nas notas explicativas que versam sobre o desenvolvimento de sinistros de cada companhia. Tendo em vista a miríade de critérios de disclosure e considerando as peculiaridades do modelo de England e Verrall (1999), o esforço empírico foi empreendido junto a cinco seguradoras que divulgaram informaçôes que permitissem a estimação do IBNP tal como definido, isto é, de que existam pelo menos dez anos de desenvolvimento de sinistros no triângulo, que o agrupamento dos sinistros se dê na forma de sinistros pagos, que o desenvolvimento dos sinistros parta do ano de ocorrência e que os dados sejam brutos de resseguro. Assim, as análises se limitam exclusivamente às seguradoras estudadas. Em particular, a Tabela 7 resume como os dados foram apresentados por essas companhias.

Tabela 7. Granularidade na divulgação das informaçôes das seguradoras analisadas.

\begin{tabular}{|c|c|}
\hline Quesito & Consideraçôes \\
\hline $\begin{array}{l}\text { Quanto ao nível de agregaçáo } \\
\text { das informaçóes }\end{array}$ & Não houve consolidação nas demonstraçóes financeiras do grupo, de modo que os dados disponibilizados são individuais. \\
\hline Quanto ao tipo de sinistro & $\begin{array}{l}\text { Duas seguradoras apresentaram os sinistros administrativos e judiciais em um mesmo triângulo, sem que houvesse uma } \\
\text { distinçáo entre eles. As três seguradoras restantes apresentaram os triângulos separadamente. Para o esforço empírico } \\
\text { empreendido nessas três seguradoras, os triângulos de pagamentos acumulados administrativos foram somados aos } \\
\text { judiciais, de modo que o critério se manteve uniforme entre as cinco seguradoras. }\end{array}$ \\
\hline Quanto ao resseguro & $\begin{array}{l}\text { As cinco seguradoras divulgaram os dados de desenvolvimento de sinistros tanto brutos quanto líquidos de seguros. } \\
\text { Como o objetivo é calcular a distribuiçáo de probabilidades associada ao IBNP e comparar com os dados reconhecidos } \\
\text { em balanço patrimonial e estes últimos sáo brutos de resseguro, o modelo empregado será feito com base nos dados brutos } \\
\text { de resseguros. }\end{array}$ \\
\hline $\begin{array}{l}\text { Quanto aos salvados e } \\
\text { ressarcimentos }\end{array}$ & $\begin{array}{l}\text { As cinco companhias explicitam que não consideram os valores relativos às despesas. Quanto a salvados e ressarcimentos, } \\
\text { quatro delas observam que os triângulos são brutos. Logo, como os dados das provisóes técnicas no balanço são líquidos } \\
\text { de salvados, um cuidado necessário foi adotado quando da comparaçáo com os dados nas demonstraçôes financeiras. } \\
\text { No caso da companhia que não discriminou se os dados estão brutos de salvados e ressarcimentos, assumiu-se que estão } \\
\text { líquidos. }\end{array}$ \\
\hline $\begin{array}{l}\text { Quanto à variabilidade dos } \\
\text { critérios de período }\end{array}$ & Os sinistros foram desenvolvidos a partir do ano de ocorrência. \\
\hline $\begin{array}{l}\text { Quanto à quantidade de } \\
\text { períodos de desenvolvimento }\end{array}$ & As cinco seguradoras apresentaram pelo menos dez anos de sinistros desenvolvidos (2010-2019). \\
\hline Quanto ao tipo de dado & $\begin{array}{l}\text { As cinco seguradoras apresentaram triângulos de desenvolvimento tanto de sinistros incorridos acumulados quanto de } \\
\text { sinistros pagos acumulados. Por opção metodológica, este trabalho simulou a distribuição de probabilidades associada ao } \\
\text { IBNP adotando o triângulo de pagamentos acumulados. }\end{array}$ \\
\hline
\end{tabular}

Nota. Elaborado pelos autores.

Os cálculos foram realizados por meio do Microsoft Excel $^{\circ}$. Neste estudo, foram feitas 10.000 estimativas de IBNP através do método de bootstrap. Foram considerados os dados de 2010 a 2019 para a consecuçáo dos triângulos de runoff (perfazendo um total de dez anos).

Com vistas a facilitar a análise de resultados, este trabalho adota o seguinte padrão:
- Seguradora A: Código Susep 06467;

- Seguradora B: Código Susep 05185;

- Seguradora C: Código Susep 06751;

- Seguradora D: Código Susep 05720;

- Seguradora E: Código Susep 06190. 


\section{RESULTADOS}

Nas Figuras 1, 2, 3, 4 e 5 são apresentadas as estimativas percentuais acumuladas de sinistros pagos para cada período de desenvolvimento de cada companhia. Tais estimativas foram criadas utilizando o método chain ladder com fatores de desenvolvimento gerados pela média ponderada dos períodos anteriores. Como resultado, os dados indicam que o desenvolvimento dos sinistros das cinco seguradoras se dá de forma similar, isto é, cerca de $94 \%$ do montante total de sinistros é pago dentro de três anos a partir do ano de ocorrência dos sinistros. Dessa forma, pode-se também inferir que as cinco seguradoras operam principalmente com seguros de cauda mais curta.

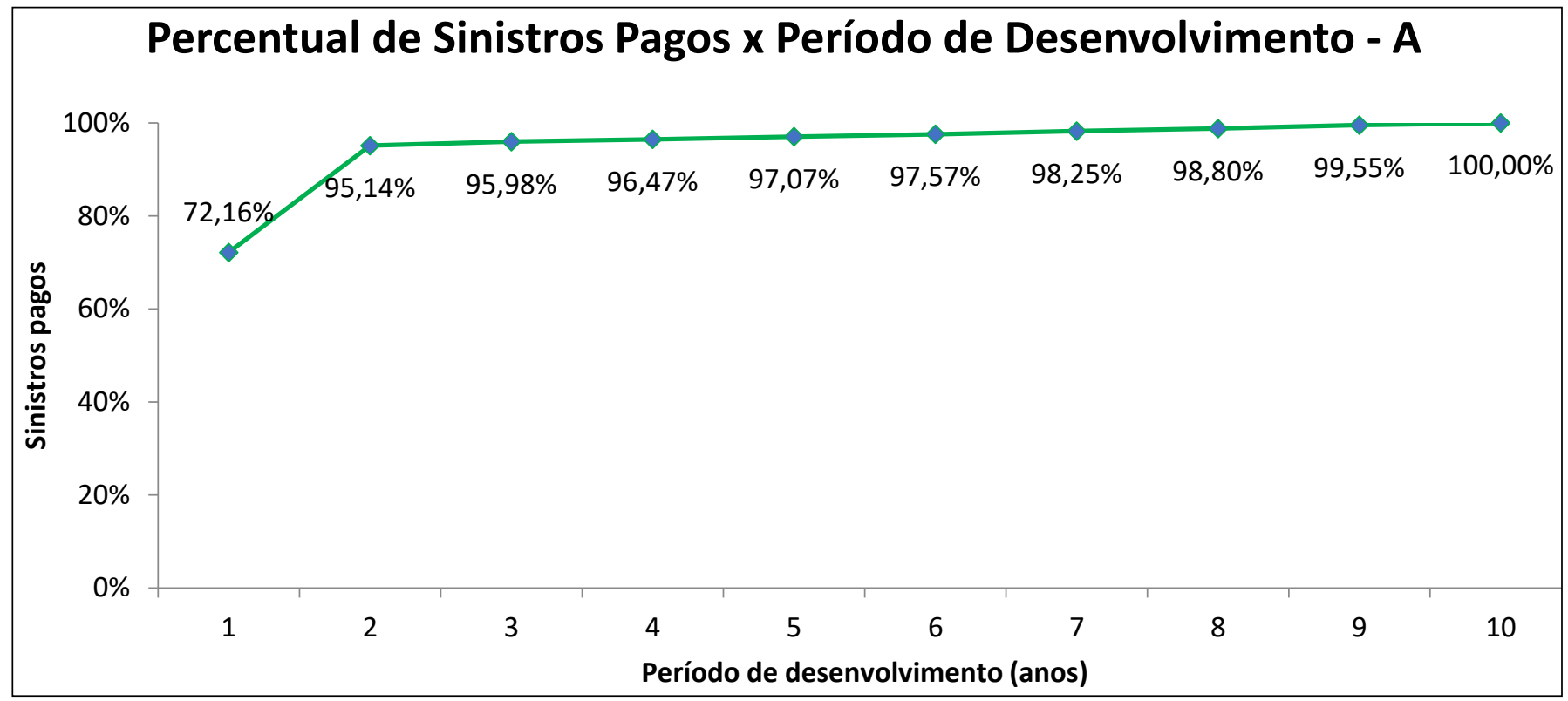

Figura 1. Desenvolvimento dos pagamentos acumulados de sinistros da seguradora A.

Fonte: Elaborado pelos autores.

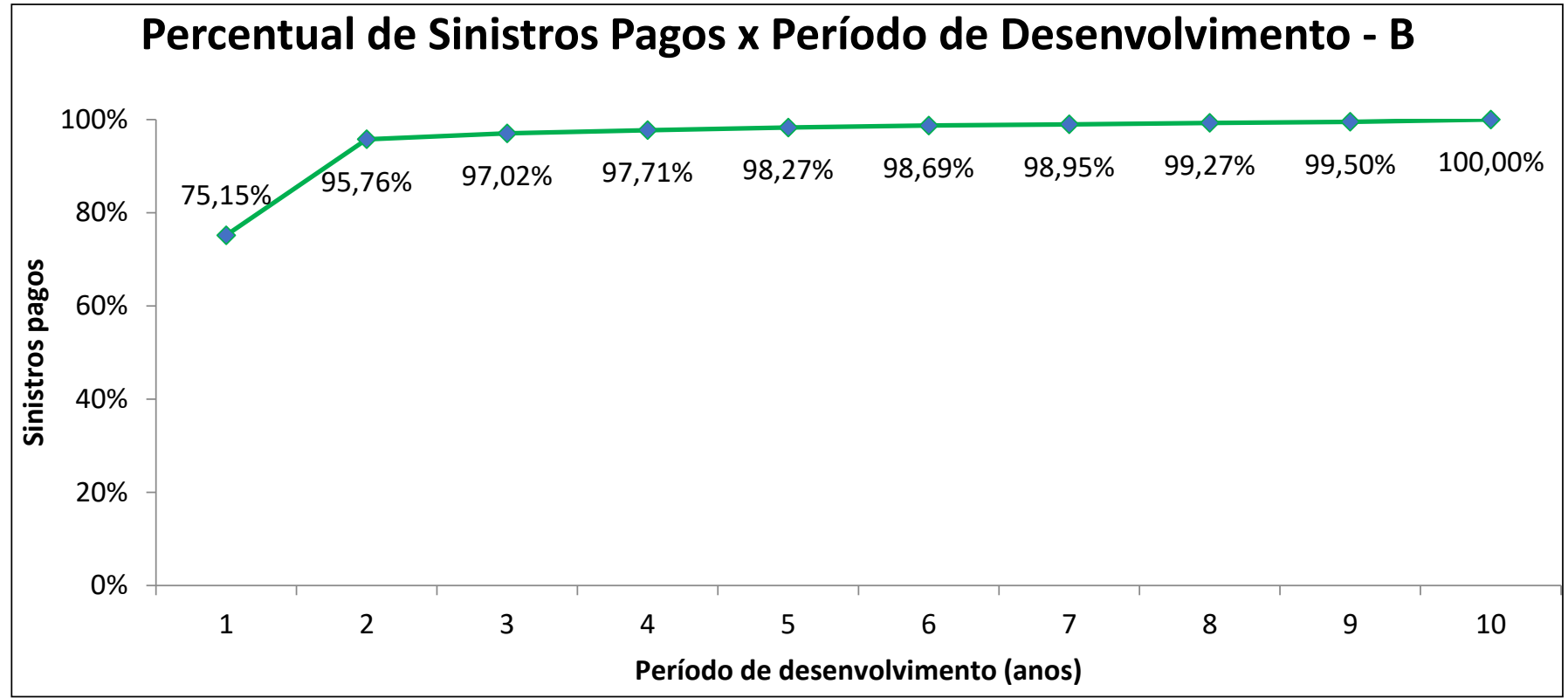

Figura 2. Desenvolvimento dos pagamentos acumulados de sinistros da seguradora B. Fonte: Elaborado pelos autores. 


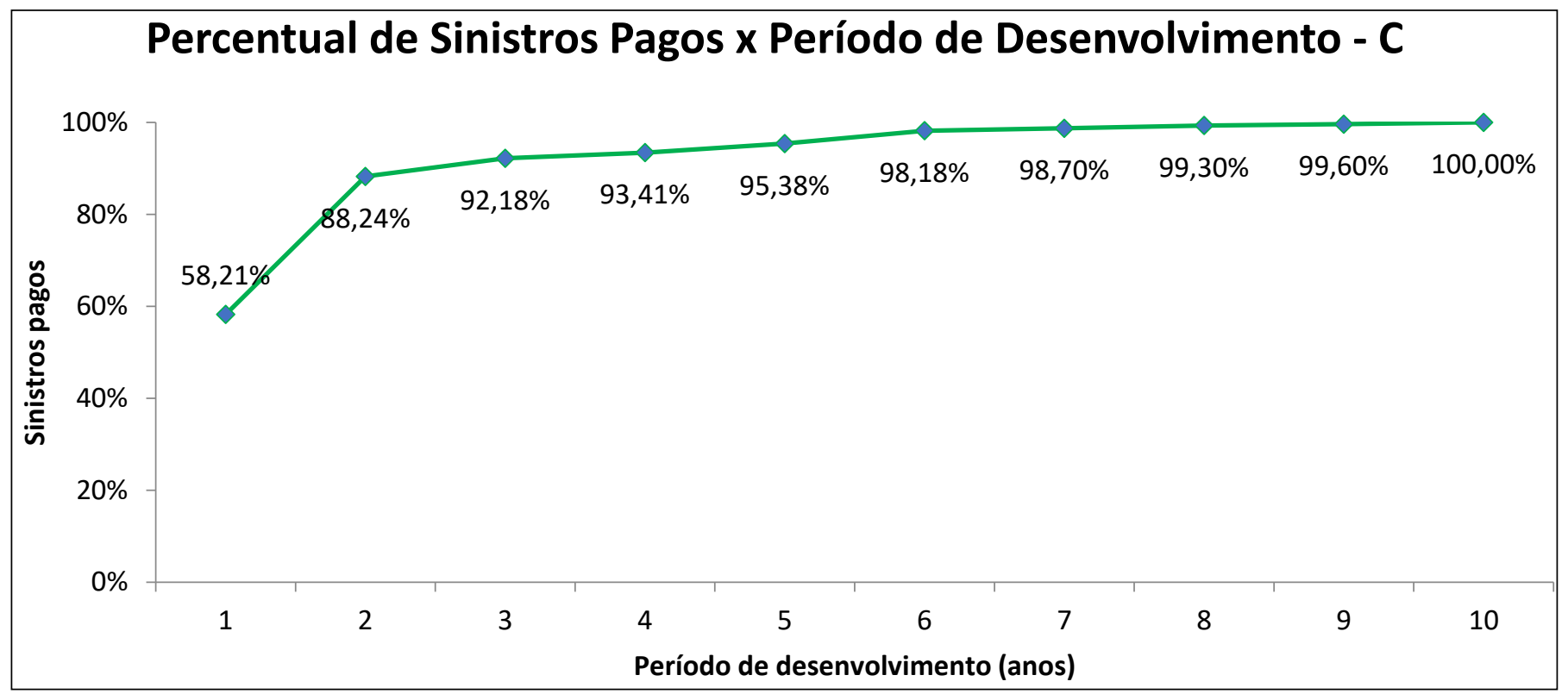

Figura 3. Desenvolvimento dos pagamentos acumulados de sinistros da seguradora C. Fonte: Elaborado pelos autores.

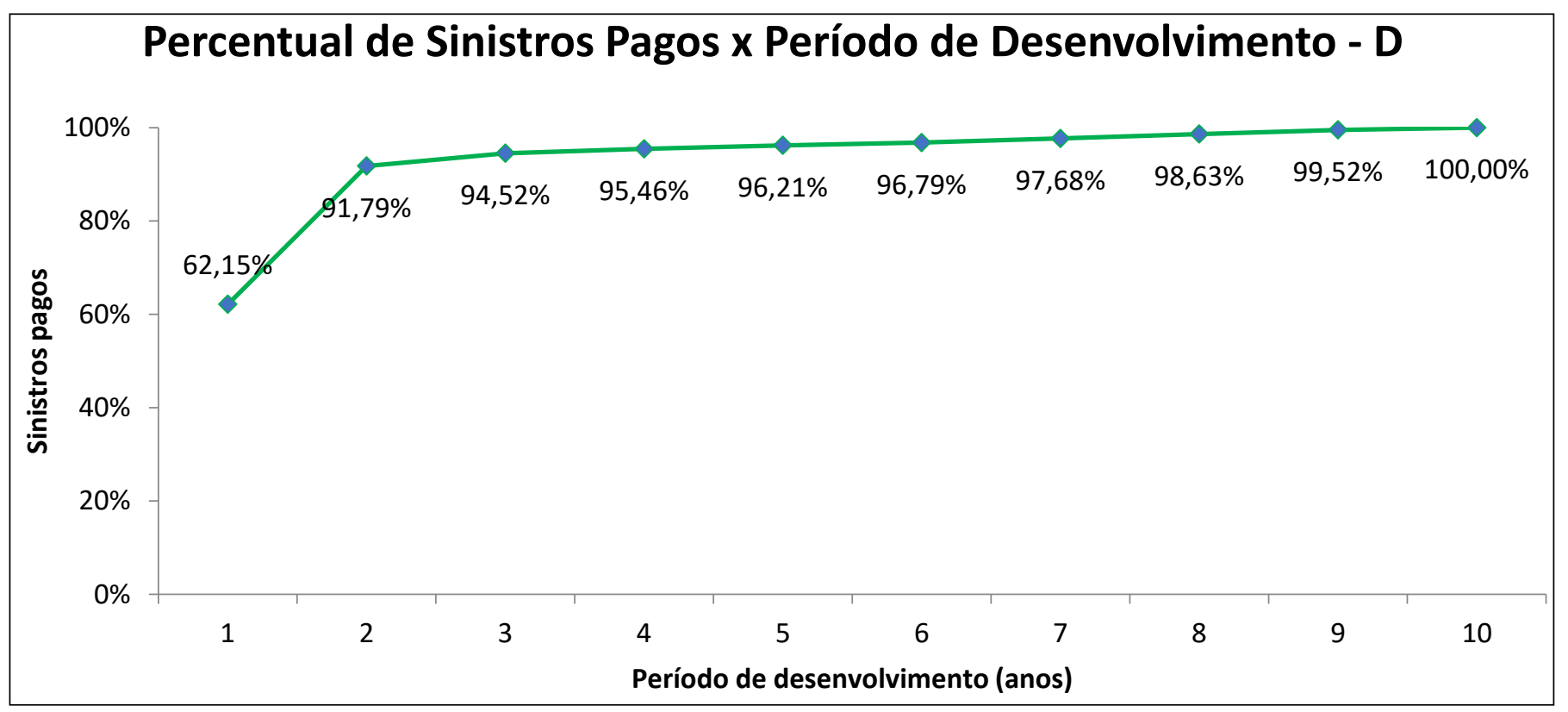

Figura 4. Desenvolvimento dos pagamentos acumulados de sinistros da seguradora D. Fonte: Elaborado pelos autores. 


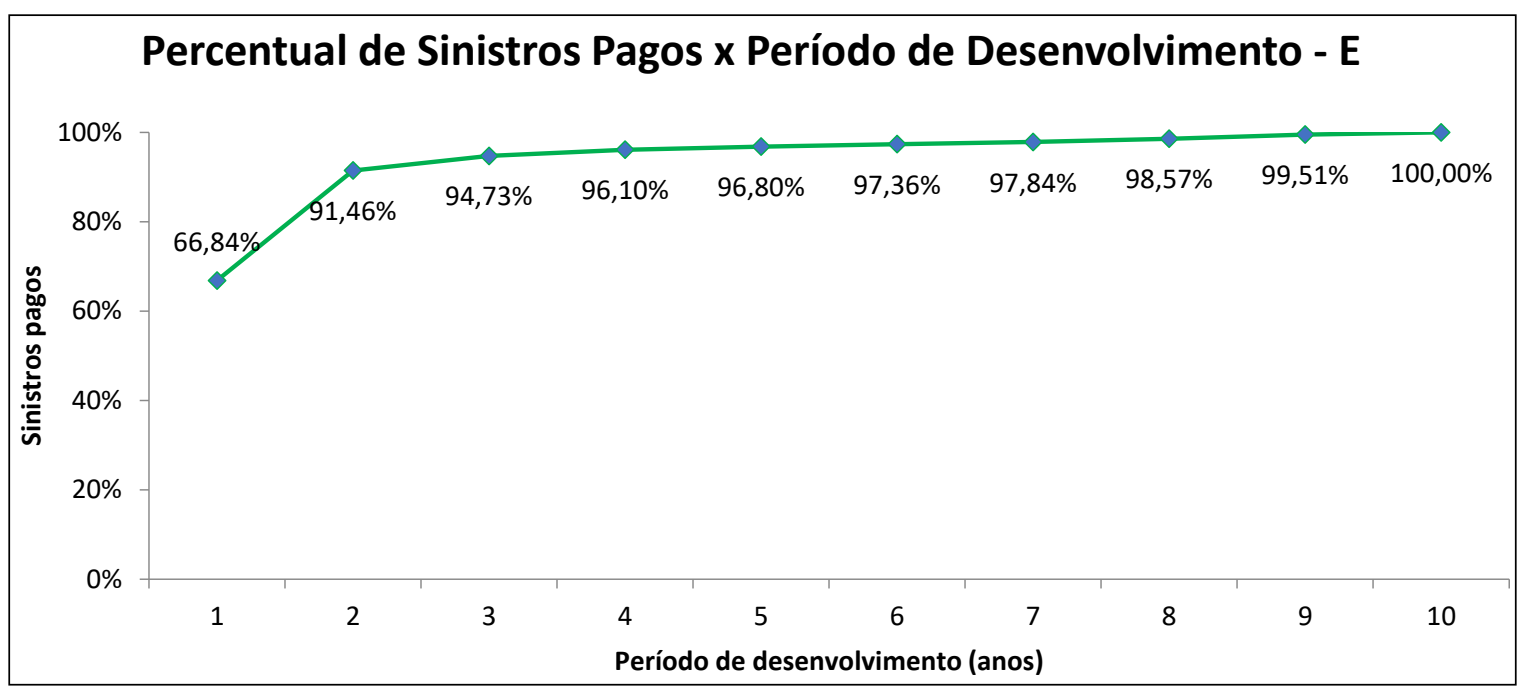

Figura 5. Desenvolvimento dos pagamentos acumulados de sinistros da seguradora E.

Fonte: Elaborado pelos autores.

Apesar de os triângulos de pagamentos acumulados de sinistros indicarem que os seguros das companhias são de cauda curta, mesmo após dez anos da ocorrência, não é possível ter a certeza de que todos os sinistros foram liquidados, já que sinistros que se tornaram judiciais podem demorar décadas até o trânsito em julgado, por exemplo. Esse é um dos motivos da importância de se identificar a distribuição de probabilidades do IBNP de uma seguradora em cada data contábil. A distribuição de probabilidades auxilia o atuário na determinação do capital baseado em risco de subscrição e também na escolha de quem, segurado ou acionista, será mais onerado para que o risco de ruína se mantenha baixo.

A Tabela 8 apresenta as principais estatísticas descritivas obtidas a partir das simulaçóes do montante de IBNP de cada companhia estudada. Podem-se observar valores positivos de curtose para as cinco companhias, indicando que as distribuiçôes são levemente leptocúrticas. Entretanto, tal como observado nas Figuras 1, 2, 3, 4 e 5, não se pode dizer que a distribuição de IBNP de nenhuma companhia estudada possua caudas pesadas, na medida em que os valores de coeficiente de curtose são próximos de zero. Não obstante, pode-se inferir também que todas as distribuiçóes também possuem uma pequena assimetria para a direita. Além disso, os coeficientes de variação das distribuiçóes de probabilidades das cinco seguradoras ficaram dentro do intervalo entre $11 \%$ e $20 \%$, o que denota uma variabilidade não táo elevada.

É imprescindível ressaltar que as seguradoras possuem portes diferentes. Isso pode ser verificado analisando-se as médias de IBNP calculadas. A título de ilustração, enquanto a seguradora $A$ apresentou uma média de IBNP de $\mathrm{R} \$$ 119,02 milhóes, a seguradora $\mathrm{E}$ apresentou uma média de $\mathrm{R}$ \$ 1.544,58 milhóes, comprovando as diferenças de porte.

Tabela 8. Estatísticas descritivas das estimativas pontuais de IBNP estimadas por reamostragem de bootstrap.

\begin{tabular}{|c|c|c|c|c|c|}
\hline Estatísticas Descritivas & Seguradora A & Seguradora B & Seguradora C & Seguradora D & Seguradora $\mathrm{E}$ \\
\hline Média (R \$ milhões) & 119,02 & 779,99 & 262,48 & $1.136,14$ & $1.544,58$ \\
\hline Percentil 50\% ( $\mathrm{R} \$$ milhóes) & 118,75 & 775,11 & 259,58 & $1.124,44$ & $1.539,17$ \\
\hline Percentil 75\% (R \$ milhōes) & 124,66 & 811,77 & 279,33 & $1.234,24$ & $1.635,88$ \\
\hline Percentil 95\% (R \$ milhões) & 134,52 & 882,46 & 314,05 & $1.424,42$ & $1.785,36$ \\
\hline Percentil 99\% (R \$ milhóes) & 142,26 & 972,00 & 342,27 & $1.614,61$ & $1.909,92$ \\
\hline Desvio padrão ( $\mathrm{R} \$$ milhōes) & 8,76 & 57,10 & 27,35 & 158,18 & 139,92 \\
\hline Coeficiênte de variação & $10,59 \%$ & $10,65 \%$ & $16,04 \%$ & $20 \%$ & $12,75 \%$ \\
\hline Curtose & 0,26 & 2,12 & 0,85 & 1,64 & 0,20 \\
\hline Assimetria & 0,24 & 0,87 & 0,67 & 0,56 & 0,24 \\
\hline Intervalo ( $\mathrm{R} \$$ milhões) & 70,41 & 471,25 & 217,03 & $1.584,88$ & $1.245,60$ \\
\hline Mínimo (R\$ milhôes) & 88,75 & 595,00 & 183,83 & 552,74 & 988,17 \\
\hline Máximo (R\$ milhôes) & 159,16 & $1.066,25$ & 400,87 & $2.137,62$ & $2.233,77$ \\
\hline
\end{tabular}

Nota. Elaborado pelos autores. 
Assim, foram gerados os histogramas com as distribuiçóes de probabilidade empíricas do IBNP realizados com os dados obtidos pela técnica de bootstrap proposta por England e Verrall (1999) para cada uma das seguradoras. Esses resultados são apresentados nas Figuras 6, 7, 8, 9 e 10.

Para cada uma das respectivas figuras, pode-se interpretar o histograma do seguinte modo: em azul, temse o percentil do montante de provisóes de sinistros brutos de salvados e resseguro reconhecidos nas demonstraçóes financeiras. Por exemplo, de acordo com as estimativas obtidas através da aplicaçáo da técnica de bootstrap, a seguradora $\mathrm{C}$ apresentou um percentil de $96,3 \%$ para o seu montante de provisóes de sinistros, isto é, estima-se que há somente uma probabilidade de $3,7 \%$ de o valor reconhecido com as provisóes de sinistros ser excedido.

Uma discussão muito importante que está atrelada às distribuiçóes de IBNP é a necessidade de capital que as seguradoras devem manter em patrimônio líquido para que se possa fazer frente ao risco de as provisóes de sinistros originalmente reconhecidas nas demonstraçóes financeiras serem excedidas. Assim, a Susep, seguindo os ditames de Solvência II, requer que todas as seguradoras mantenham um nível de capital adicional. Essa estimativa de necessidade de capital é uma das componentes do capital baseado em risco, denominada capital baseado em risco de subscrição (risco de os prêmios serem insuficientes para honrar com as indenizaçóes). De acordo com Altieri, Fraga e Veiga (2014), a necessidade de capital pode ser definida como uma reserva que fará frente a uma medida de risco da distribuição de probabilidade empírica do IBNP. Nesse âmbito, toda seguradora deve obrigatoriamente manter um nível de patrimônio líquido ajustado (PLA) ${ }^{3}$ de modo que este deve ser maior do que o maior valor entre o capitalbase e o capital de risco ${ }^{4}$. Logo, com vistas a tentar estimar o verdadeiro risco de insuficiência de provisóes de sinistros ao qual uma seguradora está submetida, em amarelo está o percentil que representa a soma do montante de provisóes de sinistros brutos de salvados e resseguros com o que a seguradora mantém em PLA. Com isso, apesar de a seguradora $\mathrm{C}$ possuir uma probabilidade estimada de $3,7 \%$ de o verdadeiro montante do IBNP exceder o reconhecido em suas demonstraçóes financeiras, quando considerado o seu montante mantido em PLA, ela possui suficiência de capital, de modo que a probabilidade de o verdadeiro valor do IBNP superar o reconhecido em provisóes técnicas (e consequentemente atrelado a algum ativo garantidor, por fins legais) e o que ela mantém em PLA converge para zero.

Convém fazer algumas ressalvas acerca do raciocínio empregado neste trabalho. O primeiro deles é que o PLA, originalmente, deve ser suficiente para evitar que se materialize não somente o risco de subscrição, mas também o risco de crédito, mercado e operacional. Com isso, a estimativa adotada possui a limitação de não considerar os demais riscos, dado que o esforço empírico se limita a analisar o risco de insuficiência das provisóes de sinistros estimadas. Entretanto, esse problema é dirimido na medida em que o risco de subscrição é a parcela mais significativa de risco ao qual uma seguradora está submetida. Analisando-se as notas explicativas de capital mínimo de risco, verificouse que para a amostra de seguradoras em tela, o risco de subscrição corresponde a aproximadamente $80 \%$ do risco de solvência ao qual as seguradoras estáo submetidas, de tal sorte que o montante do PLA, em sua maioria, destina-se justamente a cobrir esses riscos.

Outro ponto importante diz respeito ao estudo das diferenças encontradas e suas implicaçôes. Como se verifica, por meio das Figuras 6, 7, 8 e 10, as seguradoras A, B, C, e E, quando considerado o PLA, possuem baixo risco de insuficiência de provisóes de sinistros, isto é, a probabilidade de a soma do montante mantido em provisóes de sinistros e em PLA ser superado converge a zero. Contudo, o percentil referente ao montante de provisóes técnicas de sinistros varia substancialmente, indicando que há fortes indícios de que há decisóes gerenciais diferentes no que se refere à escolha de quem, segurado ou acionista, será mais onerado para que o risco de insuficiência de provisões de sinistros se mantenha baixo.

Níveis de provisóes de sinistros menores conduzem necessariamente a prêmios menores cobrados aos clientes e a lucros maiores reconhecidos no período. Nesse âmbito, a seguradora E, por exemplo, está reconhecendo um nível maior de provisóes (em termos relativos), de modo que há indícios de que elas não precisam onerar tanto os seus sócios por meio de um nível maior de PLA. Não obstante, ao reconhecer um montante de provisóes de sinistros que já possui probabilidade convergindo a zero de ser excedido, pode-se dizer que há indícios de que as provisóes estáo superdimensionadas, o que compromete a lucratividade do período e a distribuiçáo de dividendos, sendo, portanto, um exemplo de estimativas extremamente conservadoras. Por sua vez, a seguradora A possui $98,7 \%$ de probabilidade de que seu montante de obrigaçóes reconhecido em provisóes de sinistros seja superado, de modo que para manter a probabilidade de insuficiência de provisóes de sinistros igualmente baixa (convergindo a zero), a seguradora opta por manter um grande nível de PLA (em termos relativos). Do ponto de vista dos clientes, esse procedimento barateia o seguro e traz competitividade no mercado. Por sua vez, do ponto de vista do sócio, esse aparente subdimensionamento do nível de provisóes técnicas de sinistros conduz a dois fenômenos contraditórios: se, por um lado, as despesas com provisáo reconhecidas passam a ser menores e o lucro cresce, aumentando a distribuiçáo de dividendos, por outro lado, os sócios devem manter uma grande quantidade de PLA, na forma de reservas, para manter a probabilidade 
de insuficiência de provisōes de sinistros igualmente baixa, onerando-os dessa forma. Depreende-se, portanto, que o nível de provisões técnicas de sinistros reconhecido pode ser utilizado para fins de gerenciamento de resultados, tal como a literatura recente já vem explorando (Berry-Stölze, Eastman \& Xu, 2018; Hsu, Huang, \& Lai, 2019).

No tocante especificamente à Figura 9, verifica-se que a seguradora $\mathrm{D}$ possui, de acordo com o modelo elaborado, uma probabilidade de $11,2 \%$ de a soma do seu montante em provisões de sinistros com o PLA ser excedida. Contudo, duas importantes consideraçōes devem ser feitas. Inicialmente, deve-se lembrar que todas as provisões de sinistros são brutas de resseguro, de modo que uma parte dos ativos de resseguro se refere às indenizaçóes que a seguradora receberá referente a sinistros já ocorridos. Logo, na prática, toda seguradora ainda possui um montante de indenizaçóes a recuperar junto às resseguradoras. Além do ponto supramencionado, verificou-se que a situação específica da seguradora $\mathrm{D}$ se deveu a um ano atípico em sua amostra, de modo que os efeitos eram suavizados quando considerado o efeito do resseguro. Não obstante, é imprescindível deixar claro que isso se deveu a sinistros outliers que estavam cobertos por instrumento de resseguro, não se configurando, portanto, como um problema. Vale a pena complementar que o modelo de bootstrap adotado neste artigo, tal como observado anteriormente, é sensível à presença de valores extremados, de tal sorte que as estimativas podem ficar enviesadas (Lemaire, 1985). Depreende-se, dessa maneira, que os achados deste trabalho não podem e não devem ser considerados de forma individualizada, mas sim em conjunto com uma perspectiva mais ampla e que considera outras metodologias e mudanças nos negócios, tais como a introdução de novos produtos, a venda de carteiras e o eventual encerramento de contratos de parcerias.

Assim, se for considerado o montante que a seguradora mantém em provisóes técnicas de sinistros (que possui necessariamente correspondências a ativos garantidores), com o PLA e o montante a recuperar em sinistros junto às resseguradoras, a seguradora $\mathrm{D}$ passa a ter uma probabilidade de insuficiência das provisóes próxima de zero.

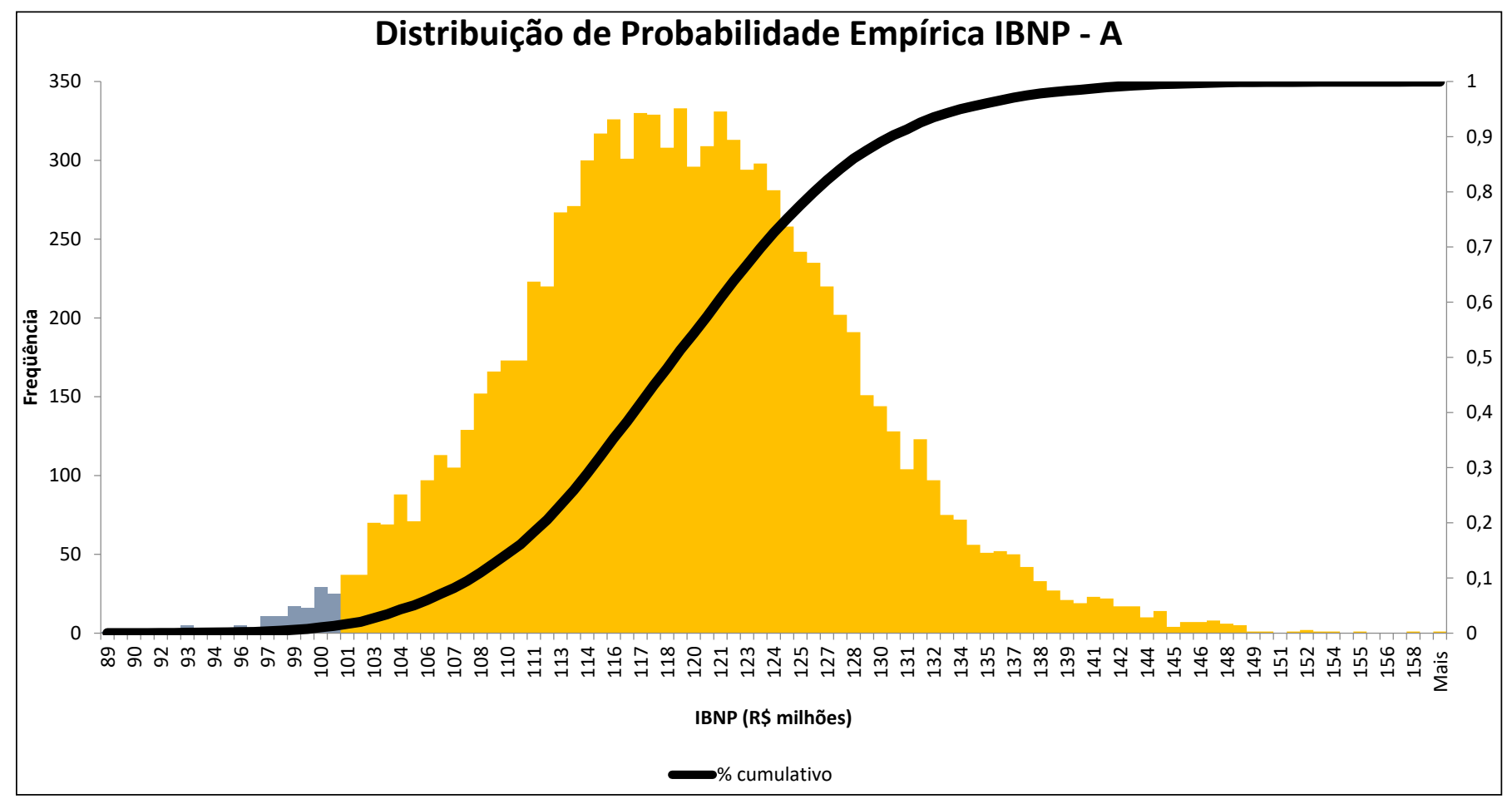

Figura 6. Distribuição de probabilidade empírica do IBNP estimado por bootstrap da empresa A.

Fonte: Elaborado pelos autores. 


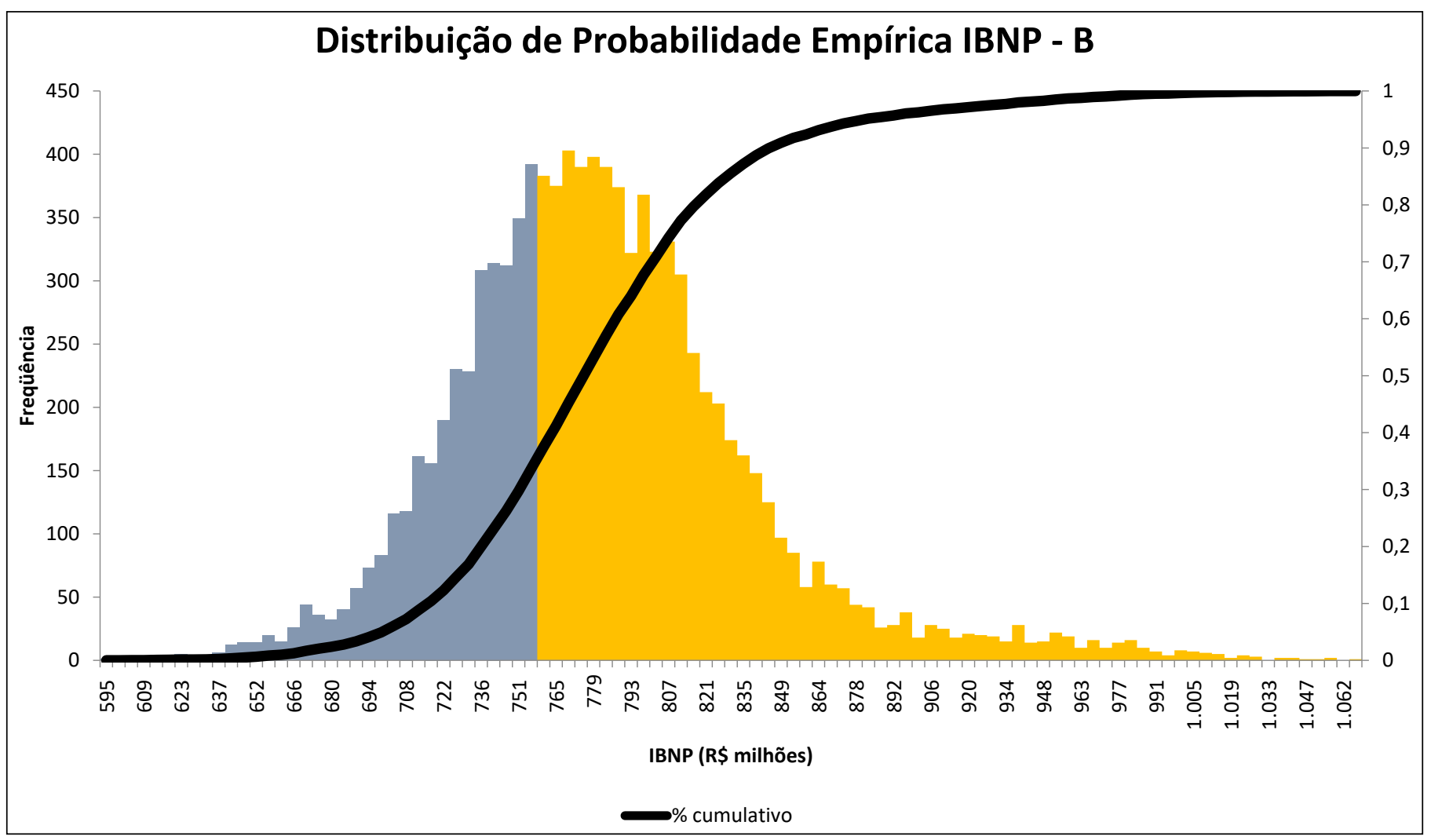

Figura 7. Distribuição de probabilidade empírica do IBNP estimado por bootstrap da empresa B.

Fonte: Elaborado pelos autores.

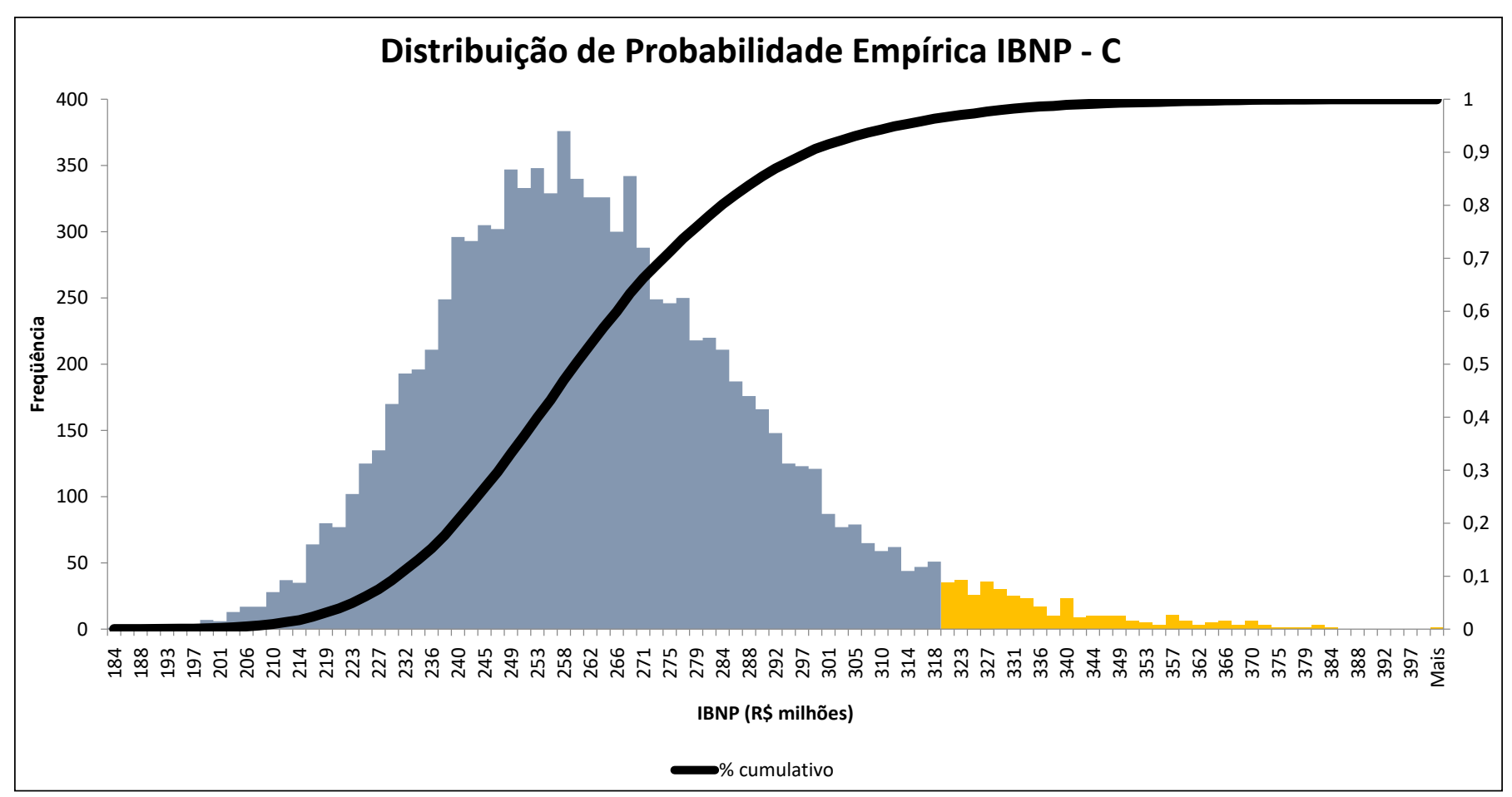

Figura 8. Distribuiçáo de probabilidade empírica do IBNP estimado por bootstrap da empresa C.

Fonte: Elaborado pelos autores. 


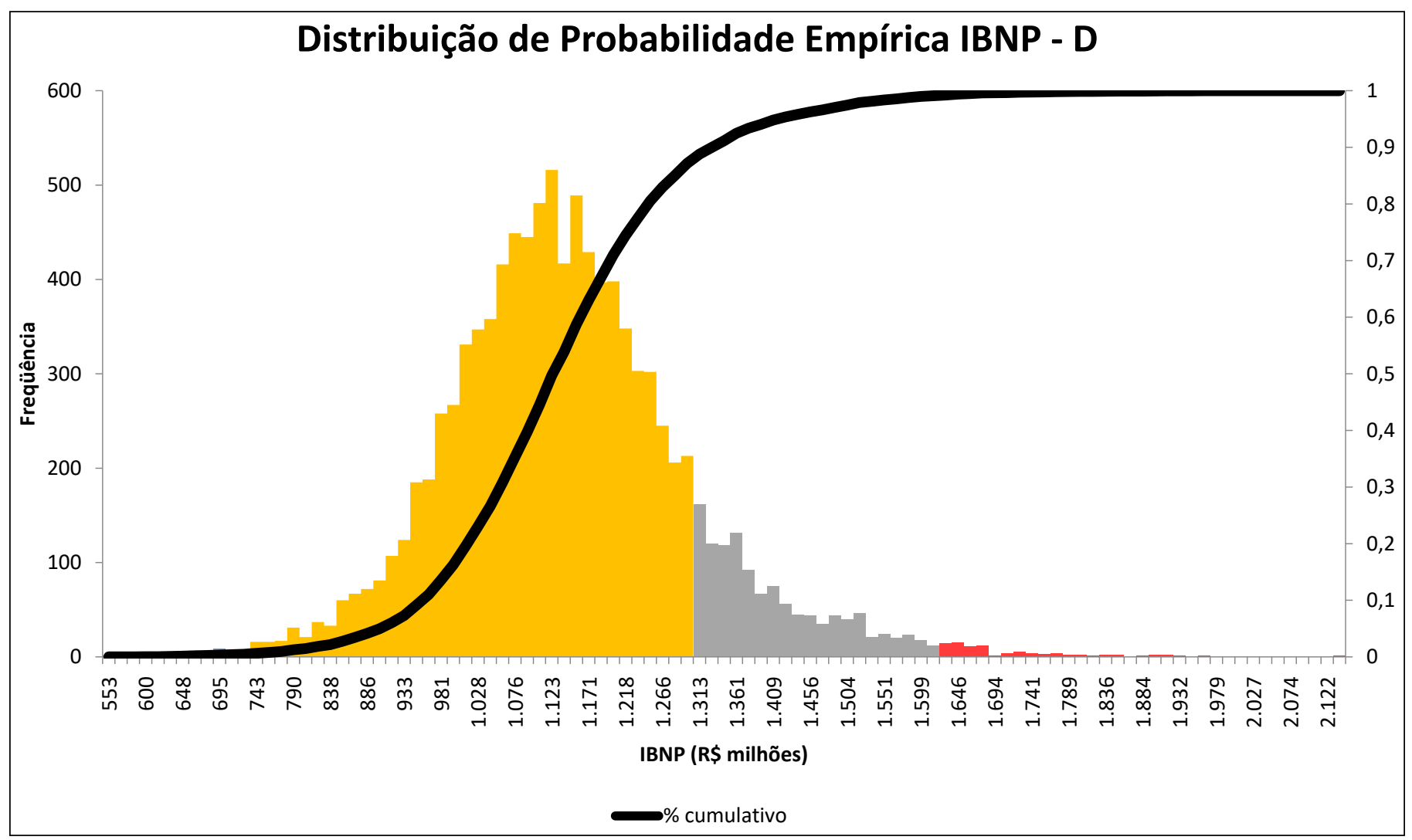

Figura 9. Distribuição de probabilidade empírica do IBNP estimado por bootstrap da empresa D. Fonte: Elaborado pelos autores.

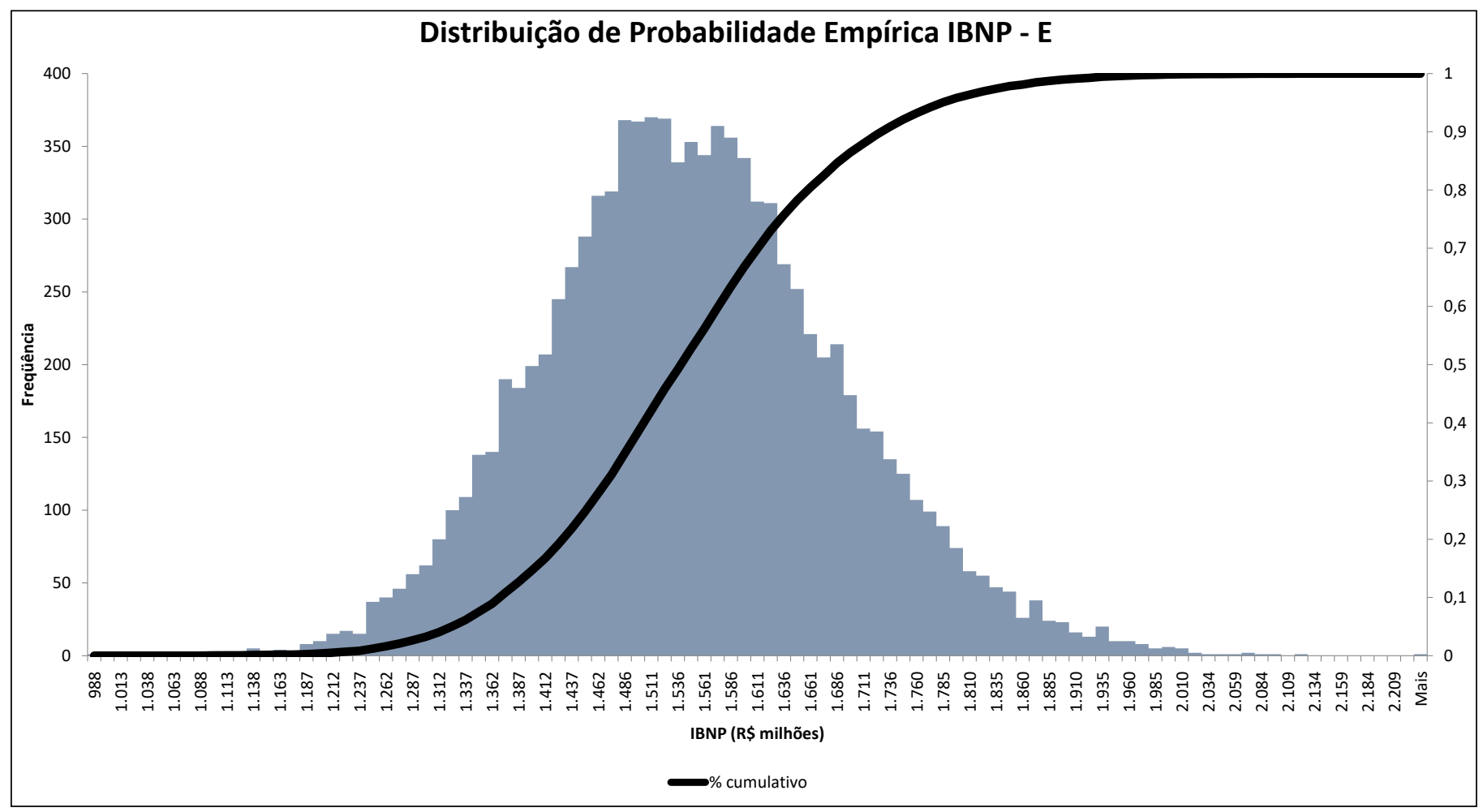

Figura 10. Distribuição de probabilidade empírica do IBNP estimado por bootstrap da empresa E. Fonte: Elaborado pelos autores. 
Conclui-se, portanto, para a amostra estudada, por meio do modelo de England e Verrall (1999) aplicado, que é possível estimar um nível de suficiência das provisóes técnicas.

Entretanto, é impreterível que se deixe claro as limitaçóes dos achados. Tendo em vista que os dados oriundos das notas explicativas congregam várias carteiras de diferentes produtos securitários, a análise passa a ser limitada pela náo granularidade das informaçóes, de modo que produtos diferentes possuem diferentes perfis de subscrição. Não obstante, o modelo em tela náo consegue capturar adequadamente a introdução de novos produtos, a venda de carteiras e o eventual encerramento de contratos de parcerias e presença de sinistros outliers, elementos estes que podem afetar substancialmente o desenvolvimento dos triângulos de sinistros pagos e consequentemente as estimativas feitas pelo método de bootstrap. Nesse âmbito, o modelo de análise sugerido pelo trabalho não substitui, sob hipótese alguma, o TAP e as eventuais insuficiências mensuradas na PCC, bem como não se constitui como uma crítica ao trabalho da administração, dos atuários das companhias e dos auditores externos (estes últimos, inclusive, dispóem das informaçóes em sua minudência para aferir com maior acurácia o nível de insuficiência das provisóes), sendo, portanto, uma proposta de metodologia para analistas externos que não dispóem das informaçóes em sua maior granularidade.

Finalmente, depreende-se que dada a falta de padronização dos critérios de divulgação, a comparação entre as seguradoras é prejudicada, de modo que a amostra de estudo se limitou a cinco casos. Ainda assim, foi possível verificar uma grande variabilidade nos achados, demonstrando como o gerenciamento de risco de subscrição varia de companhia para companhia.

\section{CONCLUSÃO}

Este trabalho partiu da seguinte indagação:

É possível inferir, por meio das demonstraçôes financeiras das entidades securitárias brasileiras, o nível de suficiência das provisóes reconhecidas por essas entidades?

Verificou-se, por meio de esforço empírico empreendido, que a falta de uniformização nos critérios de divulgaçáo das informaçôes referentes ao desenvolvimento de sinistros dificulta a aplicabilidade de modelos empíricos que permitam tal estimação. Não obstante, a falta de padronização também conduz a dificuldades nas comparaçóes da situação econômica, financeira e patrimonial das seguradoras. Contudo, a padronização não necessariamente conduz a uma maior qualidade da informação divulgada, tendo em vista que as seguradoras não necessariamente são diretamente comparáveis. Tal como assinalado anteriormente, diferentes produtos securitários possuem diferentes perfis de desenvolvimento de riscos. Logo, a criação de um padrão único tende a não capturar as especificidades associadas a cada carteira em diferentes instantes de tempo. Não obstante, a criação de um padrão de divulgação de informações contábeis deve considerar os critérios de relevância e materialidade, tal como assinalado pelo pronunciamento técnico CPC 00 (R2) (Comitê de Pronunciamentos Contábeis [CPC], 2019). Logo, os benefícios marginais associados à informação a ser produzida e divulgada devem superar os respectivos custos marginais, o que requer uma análise cuidadosa por parte da entidade elaboradora das demonstraçôes contábeis.

Foram selecionadas 31 seguradoras para a análise, sendo que elas representavam mais de $90 \%$ do cômputo de prêmios emitidos no mercado brasileiro em 2019 para seguros não vida. Após verificação de diferentes padróes de divulgaçáo, foram selecionadas cinco seguradoras nessa amostra que adotaram procedimentos similares de divulgaçáo e que permitiam a aplicação do modelo de England e Verrall (1999) para estimaçãa da funçáo de distribuição de probabilidades associada ao montante de eventos ocorridos, mas não pagos (IBNP).

Os resultados revelaram que há indícios de gerenciamento de resultados por parte das seguradoras no que diz respeito à incerteza associada às provisóes técnicas. Contudo, é imprescindível salientar novamente que o modelo adotado náo consegue capturar adequadamente a introduçáo de novos produtos, a venda de carteiras e o eventual encerramento de contratos de parcerias e presença de sinistros outliers, elementos estes que podem afetar substancialmente o desenvolvimento dos triângulos de sinistros pagos e consequentemente as estimativas feitas pelo método de bootstrap.

Logo, o trabalho pode ser visto como uma proposta de metodologia de análise da incerteza das provisóes que pode ser aplicada por usuários externos que não tenham acesso aos dados em sua maior granularidade, desde que estes estejam cientes das limitaçóes associadas.

\section{NOTAS}

1. É imprescindível entender que os sinistros incorridos podem ser definidos como a soma dos sinistros pagos e dos sinistros a liquidar.

2. O método de chain ladder aplicado ao método de sinistros incorridos não será abordado neste trabalho, apesar de sua similitude com o último.

3. Segundo o artigo $2^{\circ}$ da resolução CNSP n. ${ }^{\circ} 321$, de 2015 , inciso $\mathrm{V}$, o patrimônio líquido ajustado é o "patrimônio líquido contábil ou patrimônio social contábil, conforme o caso, ajustado por adiçóes e exclusóes, para apurar, 
mais qualitativa e estritamente, os recursos disponíveis que possibilitem às supervisionadas executarem suas atividades diante de oscilaçóes e situaçóes adversas, devendo ser líquido de ativos de elevado nível de subjetividade de valoração ou que já garantam atividades financeiras similares, e de outros ativos cuja

\section{REFERÊNCIAS}

Actuarial Standards Board. (2011a). Actuarial Standard of Practice No. 36. Retrieved from http://www.actuarialstandardsboard. org/wp-content/uploads/2014/06/asop36 secondrevision.pdf

Actuarial Standards Board. (2011b). Actuarial Standard of Practice No. 43. Retrieved from http://actuarialstandardsboard. org/wp-content/uploads/2014/07/asop043 106.pdf

Albarrán, I. L., \& Alonso, P. G. (2011). Métodos etocásticos de estimación de las provisiones técnicas en el Marco de Solvencia II. Madrid, ES: Fundación Mapfre.

Altieri, E., Fraga, E., \& Veiga, A. (2014). Modelo de cálculo da necessidade de capital para cobrir os riscos de subscrição de operaçōes não vida. Revista Brasileira de Risco e Seguro, 9(17), 1-46. Retrieved from https://www.rbrs.com.br/arquivos/rbrs $17 \quad 1 . \mathrm{pdf}$

Al-Yatama, S. K., Ali, M. S., Awadhi, K. M., \& Shamali, N. M. (2020). The effects of credit risk, operational risk and liquidity risk on the financial performance of insurance companies listed at kuwait stock exchange. European Journal of Economic and Financial Research, 3(6), 1-9. https://doi.org/10.5281/zenodo.3605377

Anker, R. A. (1973). Loss Reserving Methods. Proceedings of the Casualty Actuarial Society. Retrieved from https://www.casact.org/pubs/proceed/proceed73/73059.pdf

Balona, C., \& Richman, R. (2020). The actuary and IBNR techniques: a machine learning. SSRN. http://dx.doi.org/10.2139/ssrn.3697256

Badounas, I. \& Pitselis, G. (2020). Loss reserving estimation with correlated run-off triangles in a quantile longitudinal model. Risks, 8(1), 181-195. https://doi.org/10.3390/risks8010014

Berrar, D. (2019). Introduction to the Non-Parametric Bootstrap. Encyclopedia of Bioinformatics and Computational Biology, 766-773. https://doi.org/10.1016/B978-0-12-809633-8

Berry-Stölzle, T. R., Eastman, E. M., \& Xu, J. (2018). CEO Overconfidence and Earnings Management: Evidence from Property-Liability Insurers Loss Reserves. North American Actuarial Journal, 22(3), 380-404. https://doi.org/10.1080/10920277.2017.1421977 natureza seja considerada pelo órgáo regulador como impróprias para resguardar sua solvência”.

4. A resolução CNSP n. ${ }^{\circ} 321$, de 2015, explicita melhor os critérios de cálculo tanto do capital-base quanto do capital de risco que as seguradoras devem seguir.

Bornhuetter, R. L., \& Ferguson, R. E. (1972). The Actuary and IBNR. Proceedings of the Casualty Actuarial Society, 59, 181-195. Retrieved from https://www.casact.org/pubs/proceed/proceed72/72181.pdf

Caldas, G., Curvello, R., \& Rodrigues, A. (2016). Contabilidade dos Contratos de Seguro. Rio de Janeiro: ENS. Retrieved from https://www.ens.edu.br/arquivos/ contabilidadedoscontratosdeseguro.pdf

Carvalho, B.D., \&Carvalho,J.V.(2019). Uma abordagem estocástica para a mensuração da incerteza das provisôes técnicas de sinistros. Revista Contabilidade \& Finanças, 30(81), 409424. https://doi.org/10.1590/1808-057×201907860

Casualty Actuarial Society. (2014). Statement of principles regarding property and casualty unpaid claims estimates. Retrieved from https://www.casact.org/sites/default/files/2021-04/ Statement of Principles Regarding Property and Casualty Unpaid Claims Estimates 2021.pdf

Chase, T. R. (2015). Analysis of Bootstrap Techniques for Loss Reserving. (thesis). Fargo, North Dakota: North Dakota State University of Agriculture and Applied Science. Retrieved from https://library.ndsu.edu/ir/bitstream/ handle/10365/27842/Analysis\%20of\%20Bootstrap $\% 20$ Techniques $\% 20$ for $\% 20$ Loss $\% 20$ Reserving. pdf?sequence $=1$ \&isAllowed $=\mathrm{y}$

Christiansen, M., \& Niemeyer, A. (2014). Fundamental Definition of the Solvency Capital Requirement in Solvency II. ASTIN Bulletin, 44(3), 501-533. http://dx.doi.org/10.1017/asb.2014.10

Comitê de Pronunciamentos Contábeis. (2019). CPC 00 (R2) Estrutura conceitual para relatório financeiro. Retrieved from http://static.cpc.aatb.com.br/Documentos/573 CPC00(R2).pdf

Comitê de Pronunciamentos Contábeis. (2008). CPC 11 Correlaçâo às Normas Internacionais de Contabilidade - IFRS 4. Retrieved from http://static.cpc.aatb.com.br/ Documentos/215 CPC 11 rev\%2003.pdf

Comitê de Pronunciamentos Contábeis. (2009). CPC 25 Provisóes, passivos contingentes e ativos contingentes. Comitê de Pronunciamentos Contábeis. Retrieved from http:// www.cvm.gov.br/export/sites/cvm/menu/regulados/ normascontabeis/cpc/CPC $25 \mathrm{rev} 12 . \mathrm{pdf}$ 
Conselho Nacional de Seguros Privados (2015). Resoluçâo CNSP No 321. Retrieved from https://www2.susep.gov.br/safe/ scripts/bnweb/bnmapi.exe? router=upload/24251

Costa, J. F., \& Yui, L. M. (2018). Comparação de Métodos de Cálculo de Ibnr para uma operadora de planos de saúde através do método de análise hierárquica. Cadernos do IME - Série Estatística, 44, 19-36. https://doi.org/10.12957/cadest.2018.38491

Council of the European Union (2009). Directive 2009/138/EC. Retrieved from https://eur-lex.europa.eu/LexUriServ/ LexUriServ.do?uri=OJ:L:2009:335:0001:0155:EN:PDF

Das, S. C. (2013). Corporate social reporting and human resource disclosures: Experiences from insurance companies in India. Social Responsibility Journal, 9(1), 19-32. https://doi.org/10.1108/17471111311307796

England, P., \& Verral, R. (2002). Stochastic claims reserving in general insurance. British Actuarial Journal, 8(3), 443518. https://doi.org/10.1016/S0167-6687(99)00016-5

England, P., \& Verrall, R. (1999). Analytic and bootstrap estimates of prediction errors in claims reserving. Insurance: Mathematics and Economics, 25(3), 281-293. https://doi.org/10.1016/S0167-6687(99)00016-5

Friedland, J. (2010). Estimating Unpaid Claims Using Basic Techniques. Casualty Actuarial Society. Retrieved from https://www.casact.org/library/studynotes/Friedland estimating.pdf

Gabrielli, A. (2019). A neural network boosted double over-dispersed poisson claims reserving model. SSRN Electronic Journal, 50(1), 25-60. https://doi.org/10.1017/asb.2019.33

Hemrit, W., \&Arab, B.M.(2011). The disclosure of operational risk in Tunisian insurance companies. Journal of Operational Risk, 6(2), 69-111. https://doi.org/10.21314/JOP.2011.089

Höring, D., \& Gründl, H. (2011). Investigating risk disclosure practices in the European insurance industry. The Geneva Papers, 36(3), 380-413. http://dx.doi.org/10.2139/ssrn.1803114

Hsu, W., Huang, Y. R., \& Lai, G. (2019). Reserve Management and Audit Committee Characteristics: Evidence from U.S. Property-Liability Insurance Companies. The Journal of Risk and Insurance, 86(4), 1019-1043. https://doi.org/10.1111/jori.12251

Jackson, R. H., \& Wood, A. (2013). The performance of insolvency prediction and credit risk models in the UK: A comparative study. The British Accounting Review, 45(3), 183-202. https://doi.org/10.1016/j.bar.2013.06.009

Lemaire, J. (1985). Automobile Insurance: Actuarial Models. ASTIN Bulletin, 16(2), 186-187. https://doi.org/10.1017/S0515036100005523

Lindholm, M., Verrall, R., Wahl, F., \& Zakrisson, H. (2020). Machine learning, regression models, and prediction of claims reserves. Casualty Actuarial Society E-Forum. Retrieved from https://www.casact.org/sites/default/files/ presentation/cs22-reservescallpapers-fileid-254915.pdf
Lock, I., \& Seele, P., (2015). Quantitative content analysis as a method for business ethics research. Business Ethics: A European Review, 24(S1), S24-S40. https://doi.org/10.1111/beer.12095

Lopez, O., \& Milhaud, X. (2020). Individual reserving and nonparametric estimation of claim amounts subject to large reporting delays. Scandinavian Actuarial Journal, 2021(1), 1-20. https://doi.org/10.1080/03461238.2020.1793218

Mack, T. (1993). Distribution-free calculation of the standard error of chain ladder reserve estimates. ASTIN Bulletin, 23(2), 213-225. https://doi.org/10.2143/AST.23.2.2005092

Malafronte, I., Starita, M. G., \& Porzio, C. (2016). The nature and determinants of disclosure practices in the insurance industry: Evidence from European insurers. International Review of Financial Analysis, 45, 367-382. https://doi.org/10.1016/j.irfa.2015.02.003

Mano, C. C., \& Ferreira, P. P. (2009). Aspectos atuariais e contábeis das provisóes técnicas. Rio de Janeiro, RJ: ENS. Retrieved from https://www.ens.edu.br/publicacoes-detalhes/119

McClenahan, C. L. (2003). Estimation and application of ranges of reasonable estimates. Proceeding of Casualty Actuarial Society Forum, 60. pp. 213-230. Retrieved from https://www.casact.org/pubs/forum/03fforum/03ff213.pdf

Mendes, A., Cardoso, R. L., Mário, P. C., Martinez, A. L., \& Ferreira, F. R. (2014). Insolvency prediction in the presence of data inconsistencies. Intelligent System in Accounting, Finance and Management, 21(3), 155-167. https://doi.org/10.1002/isaf.1352

Ramos-Pérez, E., Alonso-González, P. J., \& Nuńez-Velazquez, J. J. (2020). Stochastic reserving with a stacked model based on a hybridized Artificial Neural Network. Expert Systems with Applications, 163. https://doi.org/10.1016/j.eswa.2020.113782

Schmidt, K. D. (2006). Methods and models of loss reserving based on run-off triangles: A unifying survey. Proceedings of Casualty Actuarial Society Forum, pp. 269-317. Retrieved from https://www.casact.org/pubs/forum/06fforum/273.pdf

Skurnick, D. (1973). A survey of loss reserving methods. Proceedings of the Casualty Actuarial Society. Retrieved from https://www.casact.org/pubs/proceed/proceed73/73016.pdf

Sriram, K., \& Shi, P. (2020). Stochastic loss reserving: A new perspective from a Dirichlet model. The Journal of Risk and Insurance. https://doi.org/10.1111/jori.12311

Superintendência de Seguros Privados. (2015). Circular Susep no 517. Diário Oficial da Uniâo. Brasília, DF: Exército Brasileiro. Retrieved from https:// pesquisa.in.gov.br/imprensa/jsp/visualiza/index. jsp?jornal=1\&data $=11 / 08 / 2015$ \&pagina $=19$

Sürdü, F. B., Çalışkan, A. Ö., \& Emel, E. (2020). Human resource disclosures in corporate annual reports of insurance companies: A case of developing country. Sustainability, 12(8), 3452. https://doi.org/10.3390/su12083452

Taylor, G. C., \& Ashe, F. R. (1983). Second moments of estimates of outstanding claims. Journal of Econometrics, 23(1), 3761. https://doi.org/10.1016/0304-4076(83)90074-X 
Ullah, M. S., Muttakin, M. B., \& Khan , A. (2019). Corporate governance and corporate social responsibility disclosures in insurance companies. International Journal of Accounting \& Information Management, 27(2), 284-300. http://dx.doi.org/10.1108/IJAIM-10-2017-0120

Veras, B. S. (2016). Evidenciação de contratos de seguros e passivo atuarial em seguradoras brasileiras para a data base de 31 de Dezembro de 2015 (trabalho de conclusáo de curso). Brasília, DF: Universidade de Brasília. Retrieved from https://bdm.unb.br/handle/10483/16140

Verrecchia, R. E. (2001). Essays on disclosure. Journal of Accounting and Economics, 32(1-3), 97-180. https://doi.org/10.1016/S0165-4101(01)00025-8

\section{Autoria}

\section{Roberto Bomgiovani Cazzari*}

Universidade Federal de São Paulo, Escola Paulista de Política, Economia e Negócios

Rua Oleska Winogradow, n. 100, Jardim das Flores, 06120-042, Osasco, SP, Brasil

E-mail: roberto.cazzari@unifesp.br

(D) https://orcid.org/0000-0001-8751-0203

\section{Guilherme Rodovalho Fernandes Moreira}

Universidade Federal de São Paulo, Escola Paulista de Política, Economia e Negócios

Rua Oleska Winogradow, n. 100, Jardim das Flores, 06120-042, Osasco, SP, Brasil

E-mail: grfm06@gmail.com

(D) https://orcid.org/0000-0002-1476-0954

* Autor Correspondente

\section{Financiamento}

Os autores relataram que não houve suporte financeiro para a pesquisa deste artigo.

\section{Conflito de Interesses}

Os autores informaram que não há conflito de interesses.

\section{Direitos Autorais}

A RAC detém os direitos autorais deste conteúdo.

\section{Método de Revisão por Pares}

Este conteúdo foi avaliado utilizando o processo de revisão por pares duplo-cego (double-blind peer-review). A divulgaçáo das informaçóes dos pareceristas constantes na primeira página e do Relatório de Revisão por Pares (Peer Review Report) é feita somente após a conclusão do processo avaliativo, e com o consentimento voluntário dos respectivos pareceristas e autores.
Vieira, D. M. (2016). Provisão de sinistros processo de análise $e$ tomada de decisão (dissertação). São Paulo, SP: Pontífica Universidade Católica. Retrieved from http://bdtd.ibict.br/vufind/Record/PUC SP-1 fb7dc1aaf963994ecadc59a6c413df4e/Description

Wang, Z. (2020). Analysis of insurance companies performance capital structure and soundness: Evidence from the United Kingdom. Market (tese). Falmer, East Sussex, UK: University of Sussex. Retrieved from http://sro.sussex.ac.uk/id/eprint/92209/

Yuassa, V. S. (2018). Análise técnica das provisóes de técnicas e teste de adequação dos passivos para seguradoras (dissertaçáo). São Paulo, SP: Pontífica Universidade Católica. Retrieved from http://bdtd.ibict.br/vufind/Record/PUC SP-1 5de 656807b003e61df54bd8efee0d429

\section{Contribuições dos Autores}

$1^{\circ}$ autor: conceituação (igual); curadoria de dados (igual); análise formal (igual); aquisição de financiamento (igual); investigação (igual); metodologia (igual); administração de projeto (igual); recursos (igual); software (igual); supervisão (igual); validação (igual); visualização (igual); escrita rascunho original (igual); escrita - revisão e edição (igual).

$2^{\circ}$ autor: conceituação (igual); curadoria de dados (igual); análise formal (igual); aquisição de financiamento (igual); investigação (igual); metodologia (igual); administração de projeto (igual); recursos (igual); software (igual); supervisão (igual); validação (igual); visualização (igual); escrita rascunho original (igual); escrita - revisão e edição (igual).

\section{Verificação de Plágio}

A RAC mantém a prática de submeter todos os documentos aprovados para publicação à verificação de plágio, mediante o emprego de ferramentas específicas, e.g.: iThenticate.

\section{Disponibilidade dos Dados}

Os autores afirmam que todos os dados utilizados na pesquisa foram disponibilizados publicamente, e podem ser acessados por meio da plataforma Harvard Dataverse:

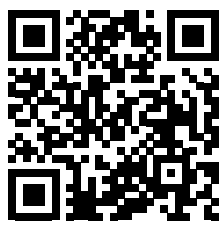

Cazzari, Roberto Bomgiovani; Moreira, Guilherme Rodovalho Fernandes, 2021, "Replication Data for: "Uncertainty of Claims Provisions from the Analysis of Financial Statements" published by RAC-Revista de Administração Contemporânea", Harvard Dataverse, V1. https://doi.org/10.7910/DVN/OSMMTI

A RAC incentiva o compartilhamento de dados mas, por observância a ditames éticos, não demanda a divulgação de qualquer meio de identificação de sujeitos de pesquisa, preservando a privacidade dos sujeitos de pesquisa. A prática de open data é viabilizar a reproducibilidade de resultados, e assegurar a irrestrita transparência dos resultados da pesquisa publicada, sem que seja demandada a identidade de sujeitos de pesquisa. 